Cómo citar este trabajo: Binimelis Sebastian, J. (2019). La transición post-productivista del sector vitivinícola de Mallorca (1990-2015). Boletín de la Asociación de Geógrafos Españoles, 80, 2725, 1-37. http://dx.doi.org/10.21138/bage. 2725

\title{
La transición post-productivista del sector vitivinícola de Mallorca (1990-2015)
}

\author{
The post-productivist transition \\ of Mallorca's winemaking sector (1990-2015) \\ Jaume Binimelis Sebastian \\ jaume.binimelis@uib.es \\ Departamento de Geografía \\ Universitat de les Illes Balears (España)
}

\section{Resumen}

Este trabajo analiza la fase más reciente en la evolución del sector vitivinícola en Mallorca, centrándose en la creación de una nueva viticultura ligada a la producción de vino de calidad. Su desarrollo, a partir de los años noventa del siglo pasado, se ha realizado al amparo de los planes de reestructuración del viñedo y de la creación de Denominaciones de Origen y otras Indicaciones Geográficas. A su vez, hemos asistido al desarrollo atomizado de una nueva industria de transformación, formada en gran parte por pequeñas bodegas, de escasa capacidad, que cuentan con sus propios viñedos. La vinculación del producto al lugar, reflejada en las normativas de las indicaciones geográficas, y los cambios de la industria crean un nuevo modelo con características muy ligadas a lo que se denomina tránsito post-productivista. En el artículo se analizan sus claves, que se manifiestan en la viticultura, en el paisaje vitícola y en la industria de transformación.

Palabras clave: viñedo; industria del vino; post-productivismo; Mallorca.

\begin{abstract}
Mallorca's centuries-old tradition of vine-growing and wine-producing has undergone different stages in its evolution, some involving expansion and others contractions. This study analyses the most recent phase in the sector's evolution in Mallorca, focused on a new approach to viticulture
\end{abstract}


associated with the production of high-quality wines. This phase was developed as from the 1990s in line with plans for the restructuring of vineyards and the creation of Designations of Origin and other Geographical Indications. In turn, we have been able to witness the fragmented growth of a new wine-making industry, largely made up of small low-capacity wineries with their own vineyards. The products' links with the area where they are produced through legislation governing geographical indications and changes in the industry have led to the creation of a new model, with characteristics closely tied in with what is known as the post-productivist shift. In the paper, an analysis is made of the keys to the new model, evident in the vine-growing process and landscape and in the winemaking industry.

Key words: vineyard; winemaking industry; post-productivism; Mallorca.

\section{Introducción}

En la actualidad las actividades agrarias son en Mallorca actividades marginales. En las décadas de los sesenta y los setenta la modernización de la agricultura fue un proceso selectivo, dando lugar a la pauperización de determinados sectores agrícolas ligados a modelos de producción obsoletos agricultura extensiva de secano- o también al desarrollo de otros subsectores vinculados a las nuevas demandas generadas por el turismo y la urbanización -agricultura intensiva de regadío-. Sin embargo, hacia mediados de la década de los ochenta la actividad agraria sin ningún tipo de excepción inició una etapa de abandono y de estancamiento absoluto. Paralelamente al ingreso de España en la Unión Europea, la conversión de los espacios rurales en espacios residenciales, así como la continua sangría de efectivos agrarios como consecuencia del envejecimiento de la escasa población activa agraria, explican la nueva situación.

Las características del subsector vitivinícola se ajustan al marco general antes explicitado, con algunos rasgos específicos. El cultivo de la vid, secular en la isla de Mallorca, ha experimentado distintas fases en su evolución, de expansión algunas y de retracción otras (Binimelis, 2014). No obstante, el sector ha vivido una nueva etapa de crecimiento que llega hasta la actualidad y que tiene su punto de inflexión a finales de los años ochenta del siglo pasado. Esta etapa de desarrollo de una nueva viticultura, se caracteriza por el predominio de variedades foráneas, y de una industria de transformación de pequeñas bodegas dedicadas a la producción de vino de calidad, todo bajo la protección institucional de indicaciones geográficas de nueva creación. Su inicio coincide con el arranque, subsidiado con ayudas procedentes de Europa, de casi la totalidad de la superficie vitícola plantada en las décadas de modernización e industrialización del sector, que comienza en las primeras décadas del siglo XX, y tiene su momento álgido en las décadas de los sesenta, setenta y ochenta del pasado siglo. Nuestra hipótesis de trabajo defiende que las 
características de la nueva viticultura, así como las de la industria del vino, se inscriben, con matices, en lo que se ha denominado post-productivismo.

El trabajo se subdivide en cuatro grandes apartados. En la primera parte, reflexionamos sobre la discusión del significado del paradigma post-productivista, y de algunas de las características del "quality turn"1 en relación con el devenir del sector vitícola. En el segundo apartado, explicamos los objetivos del trabajo, la hipótesis que planteamos, la procedencia y naturaleza de los datos usados, así como los procedimientos llevados a cabo en su elaboración. En la tercera sección, desarrollamos el trabajo propiamente dicho, analizamos el sector vitícola insular en su etapa más reciente, y probamos sus vínculos con las características del paradigma post-productivista. Por último, dedicamos la cuarta parte a la elaboración de las conclusiones del trabajo.

\section{Tránsito post-productivista e identidad. El terroir y las denominaciones de origen, eje del debate en la Geografía del vino.}

\subsection{Tránsito post-productivista}

La elaboración del concepto del post-productivismo recorrió tres etapas desde su primera formulación a principios de los 90 del siglo XX (Morris \& Evans, 1999). En una primera etapa, se utilizó el término para referirse a las estrategias de ajuste de las explotaciones agrarias frente las nuevas condiciones del sector agropecuario. En una segunda, se definió el post-productivismo con cinco categorías (Evans et al., 2002): a) la transformación de una producción agraria cuyo aliciente era la cantidad hacia la insistencia en la calidad; b) el desarrollo de la pluriactividad (diversificación agrícola y empleo no agrícola); c) la extensificación y la progresiva tendencia al desarrollo de una agricultura sostenible amparada en las políticas agroambientales; d) la dispersión de los patrones de producción y, e) el descenso del apoyo financiero de la Administración hacia la agricultura. Finalmente, se desarrolló una teoría de la transición post-productivista, concebida como un cambio estructural en las condiciones de desarrollo de la agricultura en los países desarrollados. La transición fue definida a partir de la comprensión de tres dimensiones bipolares del cambio: 1. De la intensificación a la extensificación. 2. De la concentración a la dispersión. 3. De la especialización a la diversificación (Ilbery \& Bowler, 1998).

No obstante, desde su formulación el debate sobre la teoría de la transición postproductivista ha permanecido abierto. Evans (2001, p. 50) fue muy crítico con ella, manifestando su escepticismo y

1 Asociado a sistemas alternativos de producción y distribución de alimentos que operan en los márgenes del sistema industrial imperante (Holloway \& Kneafsey, 2004, pp. 267 y 268). Por otra parte, la calidad alimentaria, característica propia del post-productivismo y de los procesos de patrimonialización e identidad, está relacionada con el resurgimiento de la investigación de la agricultura desde una perspectiva cultural. En los años 90 los temas rurales dominaron frente a los agrícolas, al contemplar el campo más como un lugar de consumo que como lugar de producción. Sin embargo, a partir del inicio de siglo regresamos, de nuevo, al interés hacia la agricultura (Morris, 2004, p. 243). 
poniendo serias trabas a la existencia de evidencias empíricas irrefutables a las tres dimensiones bipolares del cambio, además de considerar el concepto como un cul de sac desde el punto de vista teórico. A pesar de ser la calidad alimentaria un valor cada vez más importante, Evans afirmó que la detección de un aumento de la demanda de productos de identidad local sólo satisfacía un nicho limitado de demanda. La controversia se alargó y, también, se discutió si el término era el adecuado para definir y caracterizar el cambio. Por ello, Wilson acuñó el concepto de régimen agrícola multifuncional y Evans el de modernización ecológica. Mientras, Mather et al. (2006, p. 452) defendió la validez como marco teórico del post-productivismo, cuyas concreciones más evidentes de transformación se darían en el ámbito de la agricultura, pero también en el espacio forestal y en los usos del suelo en general.

Más profundo fue el análisis de Mark Tilzey u Clive Potter (2008). Para ellos, el post-productivismo es una faceta en la transición del fordismo al post-fordismo, y expresa el selectivo declinar de la agricultura productivista bajo las condiciones de competencia global y una respuesta a sus contradicciones medioambientales y sociales. Nace en las transformaciones en el patrón de la gobernanza y regulación de la agricultura que aparecieron desde los años ochenta del siglo XX. La reglamentación neoliberal creó excepciones en los espacios donde la competitividad global no permitía el desarrollo de la actividad agraria bajo las premisas de una economía de escalas productivista. Por tanto, en las áreas económicamente marginales se han favorecido experiencias post-productivas, mientras que la agricultura industrializada es característico de las áreas económicamente favorables. El post-productivismo no es una fórmula alternativa y antitética del productivismo dominante, sino que se integra en él a través de normas de regulación estatal.

La controversia, sin dudas, ha persistido hasta nuestros días. Centrándose en ejemplos de los países nórdicos, Almstedt et al. (2014) consideran que la vasta mayoría del espacio rural es para un uso productivo, aunque parte de él se haya convertido en reservas naturales u otros usos no productivos. La explotación forestal moderna altamente mecanizada es claramente una evidencia de la persistencia de la filosofía productivista. No obstante, esas actividades productivas no crean trabajos y no dan lugar a un cambio de signo en la despoblación rural. Por ello, las antiguas granjas se convierten en segundas residencias que, a su vez, han creado la demanda de servicios relacionados con el turismo.

Por otro lado, el prefijo post ha creado grandes suspicacias, porque supone la sucesión lineal de modelos diferenciados. Se apuesta por el nuevo término no-productivismo que convive con el productivismo en entornos multifuncionales. La creciente globalización, los cambios de dieta, la demanda creciente de productos alimenticios ha realimentado la discusión teórica, con la aparición de nuevos términos, como son neo-productivismo y super-productivismo. Esto último, se aplica a nuevas experiencias intensivas que se da, sobre todo, en países pobres, como el land grabing, una nueva fase de acaparamiento de tierras protagonizado por países emergentes y por grandes 
fondos de inversión, tras la crisis alimentaria de hace unos años. El neo-productivismo se asocia a renovados planteamientos de agricultura intensiva e industrial en entornos rurales, como el europeo, que han vivido una etapa no-productivista, de extensificación de la producción en las décadas de los ochenta y los noventa, que sustituyó la etapa productivista de las décadas del desarrollismo. Más allá de esta explicación espacio-temporal, desde una óptica más estructural, se distingue entre diversos planteamientos neo-productivistas, dependiendo del régimen de política económica dominante. Para Europa se habla de productivismo sostenible o multifuncional, en Australia de productivismo competitivo y en Nueva Zelanda de productivismo cooperativo, ámbitos espaciales estos últimos, donde la implementación de políticas neo-liberales ha sido más clara y nítida que en Europa, donde ha persistido la inercia protectora hacia el agricultor y el medio rural (Wilson \& Burton, 2015).

La agricultura propia del modelo productivista dejó de estar ligada a un territorio concreto para ser una actividad globalizada (Hervieu, 1996, p. 83), como la industria, con procesos de deslocalización, concentración y estandarización. La producción industrial de alimentos, sin identificación de su procedencia, con la utilización de organismos genéticamente modificados, desencadenó la desaparición de las tradiciones gastronómicas locales, el descenso de la calidad alimenticia y la separación de la producción y del consumo. No obstante, en los años ochenta del siglo pasado surgió la fase post-productivista, o no-productivista, como respuesta al proceso de homogeneización, basado en la valoración de la idiosincrasia de los productos locales. Desde entonces se han recuperado productos tradicionales, variedades en desuso o formas locales de preparación de los productos, desde una normativa legal que protege su singularidad. Para el consumidor, la garantía del origen del producto prueba su autenticidad y su calidad. Todas estas iniciativas, ligadas a la producción de alimentos de calidad, son observadas como un nuevo paradigma para la agricultura occidental. Sus proyectos están vinculados a la herencia y, a su vez son percibidos como un instrumento de desarrollo rural. A través de la producción de nostalgia, los agricultores crean islas post-productivistas en un contexto productivista, diseñando un nuevo mapa para el consumidor del campo (Bowen \& De Master, 2011, p. 74).El énfasis que se da a la herencia cultural de los productos alimenticios es una respuesta consciente a la estandarización y las tendencias industriales de la globalización.

A dicha discusión no ha sido ajena la Geografía española. En este sentido debemos de remarcar una primera aportación de Pascual Rubio (1999) a finales de los noventa, cuando la formulación teórica sobre el post-productivismo aún no había salido de las islas británicas, para replantear en clave española, en un segundo trabajo, el significado del cambio rural una década después (Rubio, 2010). Es también meritorio el estado de la cuestión que en su momento nos ofreció Xosé Armesto (2005) ampliando el concepto no sólo a fórmulas productivas ligadas a la calidad, sino también a otros usos no productivos del territorio rural. Desde entonces, el concepto -post-productivismo- y sus 
derivados -post-productivo- han sido usados en múltiples estudios de casos. Se ha ligado la apuesta postproductivista al nuevo modelo agroambiental que ha presidido las políticas de desarrollo rural en espacios serranos, marginalizados de las políticas desarrollistas de los años sesenta y setenta ${ }^{2}$, También se analizan nuevas modalidades de producción agrícola, ligadas a la calidad alimentaria, a la sostenibilidad ambiental y a la satisfacción de determinados nichos de consumo. Destacan, sin lugar a dudas, las aportaciones realizadas sobre el sector vitivinícola, haciendo hincapié en el cambio de modelo productivo, con experiencias ligadas a la calidad y a los procesos de patrimonialización en Castilla-La Mancha (Ruiz Pulpón, 2013; Cañizares \& Ruiz Pulpón, 2014). En un estudio sobre la DO de Cigalés, se relaciona el aumento de la superficie vitícola, la aparición de las nuevas bodegas industriales, las transformaciones paisajísticas de los nuevos sistemas de formación y el auge del enoturismo (Fernández Portela, 2012). La Ribera del Duero es otra comarca vitícola que ha experimentado cambios en los planteamientos del sector vitivinícola: intensidad de la producción, cambios en los sistemas de formación, cambio tecnológico, cambios paisajísticos, bodegas de arquitectura rupturista que actúan de centro neurálgico de las nuevas áreas vitícolas, desarrollo de la restauración y de la actividad hostelera ligada al sector (Molinero \& Cascos, 2011)

\subsection{Patrimonialización e identidad, características del tránsito post-productivista.}

La inserción de productos tradicionales y específicos de un lugar en las economías modernas forma parte de un proceso llamado patrimonialización ${ }^{3}$. El concepto (Gade, 2008) expresa el interés de intelectuales urbanos y sindicatos agrícolas en la protección de paisajes rurales y productos de gastronomía tradicional. Los productos agrarios, junto con los paisajes, la arquitectura vernácula ${ }^{4}$, el saber hacer (savoir faire) y las técnicas forman los cuatro ejes del patrimonio rural (Delfosse, 2011). Otros relacionan el concepto del terroir (Barham, 2004) al creciente interés por la herencia del pasado y el patrimonio, y afirman que dicha tendencia deriva hacia un proceso de Disneyfication,

2 Es el caso de la Sierra de Huelva, comarca que fue catalogada como Parque Natural, razón que ha servido de palanca para el desarrollo diversificado de dicho territorio, con la revitalización de la industria chacinera, el emergente turismo rural y la actividad inmobiliaria de reforma y restauración de antiguas casas para segunda residencia, entre otros. Todo ello ha frenado la sangría demográfica de décadas anteriores, aunque continúa con una estructura demográfica ciertamente envejecida (Ojeda \& Silva, 2002).

3 Los procesos de patrimonialización en áreas de desarrollo y economía vitivinícola no son exclusivos del Viejo Mundo. También se da en los nuevos países productores. En Sudáfrica (Dellier et al., 2013), además del crecimiento experimentado por el área vitícola y por las exportaciones de vino, también se ha observado un proceso de africanización, con el que se busca dar una pátina de identidad a la producción, que se liga al folklore y a la cultura del país.

4 Fernández Portela y García Velasco (2014) han analizado recientemente el estado de los barrios de lagares y bodegas en los municipios que forman la DO Cigalés, a orillas del Pisuerga, en Castilla y León. Son un recurso patrimonial clave para el desarrollo rural de estos municipios, basado fundamentalmente en la oferta enoturística. A partir de 50 entrevistas elaboran una matriz DAFO sobre el estado y las potencialidades de estos elementos de arquitectura vernácula y realizan una propuesta de actuaciones que incluye su conversión en Eno-museo, Museo al aire libre, festival de bodegas tradicionales, bodega de creación artística, restaurante cultural, alojamiento rural culturas, centro de degustación enogastronómica, entre otras. 
que da lugar a una ruralidad helada, para el consumo de clientes privilegiados ${ }^{5}$, convirtiendo los espacios rurales en museos vivientes para visitantes urbanos.

Después de la era de la producción y del consumo de masas, el sector agro-alimentario segmenta la oferta de productos, y la vía tradición-terroir es un medio para ello (Delfosse, 2011, p. 226). Esta estrategia de diferenciación permite conquistar consumidores que buscan nuevos códigos alimenticios. El producto pasa a ser un indicador de la pertenencia territorial. Los productos del terroir no sirven solamente para construir una imagen interna, sino también para afirmarse a otras escalas.

El proceso de patrimonialización aparejado a la creación de denominaciones de origen conjuga mito y realidad. Por eso, en el caso de áreas vitícolas, se reivindica una antigüedad que se remonta a la época greco-romana, o se usan heráldicas en las etiquetas de los vinos, creando una imagen falsa que liga con el pasado. La continuidad histórica es errónea, porque la viticultura desapareció durante siglos. No obstante, la tradición es inventada para evocar un pasado vinícola noble que es un signo de autenticidad (Gade, 2008).

\subsection{El debate sobre el terroir}

El debate sobre el significado y las variables que influyen en la definición del terroir se ha convertido en la caja de Pandora de la Geografía del vino ${ }^{6}$. En el pasado los investigadores ponían el acento sobre las variables del medio físico, mientras que a posteriori los trabajos han enfatizado las cuestiones culturales. El territorio da al vino un sentido del lugar, razón por la cual el concepto

5 En Borgoña, desde principios del siglo XX, jurídicamente se diferencian los vinos a partir de las especificidades de los territorios donde se han producido (Delaplace \& Galetier, 2014). En la actualidad, ese proceso de patrimonialización asegura la continuidad en el tiempo y en el espacio de la viña y del vino como recursos para su valorización turística. La vinculación del desarrollo de las Denominaciones de Origen con el aumento de la actividad turística y el mayor nivel de vida de la clase media, también ha sido observado en España con el auge de la Denominación de Origen de Ribera del Duero (Huetz de Lemps, 2000).

6 Desde la década de los años noventa la Geografía del vino se ha consolidado como línea temática de investigación y reflexión geográfica. Su desarrollo en Estados Unidos es paralelo al crecimiento del consumo y al aumento de la producción. Todos los estados tienen al menos dos bodegas, y, había en total 6.785. Su incremento, constante, es consecuencia del atractivo que ejerce todo lo que rodea el mundo del vino en la sociedad americana y es atribuible tanto a sus exportaciones de vino como al incremento del consumo interno (Dougherty, 2012).

El aumento del consumo y de la producción, así como la naturaleza esencialmente geográfica del mundo vitivinícola ha permitido la consolidación y el desarrollo autónomo de esta temática de la Geografía. Desde el año 1998 existe incluso un grupo de investigación específico dedicado a ello en el seno de la Asociación de Geógrafos Americanos.

La Geografía sobre el vino está interesada en las relaciones entre el medio físico y el medio cultural con el objetivo de encontrar las razones por las que determinadas áreas producen diferentes tipos de vino. Se ha compartimentado la aportación de la Geografía en relación a la temática de la viña y del vino en siete grandes áreas: aportaciones generalistas, aportaciones desde la Geografía Regional, el papel de la Geografía Física, sobre todo Climatología y Biogeografía, Geografía Económica, Geografía Cultural, Nuevas tecnologías geográficas y el estudio del terroir (Dougherty, 2012). 
de terroir tiene gran poder geográfico porque recoge elementos del medio natural y los sintetiza con factores socio-económicos, uno de los principios básicos de la Geografía.

Tradicionalmente, el terroir es un espacio, normalmente pequeño, cuyos suelos y microclimas transfieren cualidades distintivas a los alimentos. Es un vocablo asociado a la producción de vino, que tiene su aroma y sabor genuino debido a su procedencia. En su origen responde a una situación caracterizada por una menor movilidad, cuando el cambio se producía de forma más lenta (Barham, 2003, p. 130). Los productores de un terroir desarrollan técnicas y habilidades que son consecuencia de un largo recorrido y representan la interrelación de la curiosidad humana con los recursos naturales del lugar.

Hay periodistas especializados, como Robinson y Parker (Daugerthy, 2012) que conceden gran importancia al suelo, a la topografía local y al clima, por tanto, a las características físicas de la región vitícola. El vino es demasiado complejo para que una sola variable, como el clima o el suelo, definan su personalidad. La importancia que se ha dado a las características ambientales pone de manifiesto la tenacidad y la inercia del determinismo geográfico. Sin embargo, los estudios recientes han restado peso a la óptica ambiental de la geografía del vino. Según Sommers ${ }^{7}$ terroir es usado para describir todas las características de un lugar que, en conjunto, tienen una influencia distintiva que se puede saborear en el vino.

Otro punto de discusión es la escala. A gran escala, el terroir tiene gran sentido, dando lugar a vinos diferentes procedentes de parcelas separados sólo por un camino. En cambio, a pequeña escala, cuando el vino es fruto de la mezcla de vinos procedentes de lugares alejados entre sí, como es el caso de Australia, el concepto pierde exactitud.

No hay acuerdo entre los geógrafos sobre su validez ${ }^{8}$. El abanico va desde los que creen que es una herramienta de marketing o aquéllos que creen que la parcela de viña es la razón del carácter del vino. Aun así, la idea es absolutamente geográfica porque integra elementos físicos y culturales (Dougerthy, 2012)

La discusión sobre el terroir se remonta a la Antigüedad Clásica y su persistencia en la actualidad, es consecuencia de varias controversias, que sucintamente se pueden resumir en lo que sigue (Unwin, 2012):

7 Citado por Daugherty (2012). En este apartado, seguimos de cerca la aportación que, a modo de estado de la cuestión, realiza este autor sobre la actual efervescencia de la Geografía del vino.

8 Incluso los hay que son claramente escépticos. Gade (2008) en su trabajo sobre la DO de Cassis, concluye que el ph alto de los suelos y el asfixiante sol del Mediterráneo, que son condiciones ambientales negativas para la elaboración de buen vino, no han descartado la región de su personalidad vitivinícola. De hecho, es la tercera DO más antigua de Francia. 
Agricultura frente a enología. Hasta la primera mitad del siglo XX, los viticultores también producían su vino. A partir de la segunda mitad, ambas esferas se distancian, y se enfatiza la importancia de la ciencia del vino. Esto apuntala y permite su desarrollo autónomo hasta la actualidad. Por otra parte, con el uso de los injertos sobre pie americano, la agricultura triunfó frente a las hipotéticas soluciones químicas en la lucha contra la filoxera, piedra de toque en Europa de la creación de legislación sobre el vino basada en la diferencia que hay entre lugares. Así, surgió el pulso entre las normativas restrictivas de las denominaciones de origen, basadas en la limitación de la producción y en la protección de variedades locales, y la innovación científica, partidaria de una filosofía desreguladora. Los defensores del avance científico en el ámbito enológico, apuntan que las normativas restrictivas coartan la innovación y dan lugar, muchas veces, a vinos mediocres.

Viejo mundo frente a Nuevo mundo. En el Nuevo mundo la expansión de la viña se hizo pensando en las condiciones aptas para el crecimiento, desde un punto de visto climático, más que en las condiciones edáficas, responsables de la calidad de las uvas y de los vinos. Por ello, el desarrollo de la superficie vitícola en el Nuevo Mundo ha dado preeminencia a la ciencia del vino, cuyos protagonistas, los enólogos, han mezclado vinos para obtener un buen producto en la relación calidad/precio, destinados, en general, a consumidores de países sin viñas.

\subsection{En busca de la identidad: Indicaciones Geográficas y Denominaciones de Origen ${ }^{9}$}

El concepto de terroir es tan aceptado, sobre todo en Europa, que se ha construido un aparato normativo para definir regiones específicas. Los franceses, españoles e italianos tienen las Denominaciones de Origen y, en Estados Unidos, existen las Áreas Vitícolas Americanas.

Desde el Acuerdo General sobre Aranceles Aduaneros y Comercio (GATT) de 1994, se intensificó la larga disputa entre Estados Unidos y la Unión Europea, que, sin lugar a dudas, ha tenido repercusiones sobre el desarrollo rural de forma global. En dicho acuerdo, figuran cláusulas relativas a la propiedad intelectual, donde fueron incluidas las Indicaciones Geográficas. Éstas se definen como instrumentos que identifican un producto como genuino de un país, región o localidad, siendo su calidad, reputación u otras características, atribuibles a su origen geográfico.

Las DO (tipología más conocida de IG) son usadas, sobre todo, para el vino y otras bebidas alcohólicas, pero, también, para productos alimenticios. En Europa los productos tradicionales o típicos se acogen a ellas. La literatura sobre agricultura y alimentación (Barham, 2003) contiene

9 En el texto usamos el acrónimo DO, para referirnos a las Denominaciones de Origen y el de IG para referirnos a las Indicaciones Geográficas. Por otra parte, usaremos IGP para referirnos a Indicaciones Geográficas Protegidas. Ambas son certificaciones que se utilizan para identificar ciertos alimentos con características propias y diferenciarlos debido a su origen geográfico. La Denominación de Origen nos indica que sus características son especiales gracias al medio en el que se producen, y además su transformación y elaboración se realiza en ese mismo lugar. Mientras, la Indicación Geográfica Protegida hace referencia, también, a alimentos que tienen atributos singulares por su origen geográfico. La diferencia radica en que en la Indicación Geográfica Protegida se exige el origen del producto, no siendo necesario que el procesamiento del producto sea realizado en esa zona delimitada. 
muchas referencias sobre el crecimiento de la demanda de estos productos tradicionales y de calidad, como la evidencia de la emergencia de un nuevo paradigma de desarrollo rural. Los productos de DO son expresiones de desarrollo de sistemas de alimentación alternativos, endógenos, locales y ligados a la calidad. Son, por otra parte, manifestaciones del consumer turn, que es el mayor cambio en el modelo agrícola convencional. La producción global agrícola pertenece a un sistema bipolar, con un alto volumen de alimentos de consumo diario, elaborados y distribuidos por corporaciones multinacionales, y un nicho menor de productos especializados que representan un $30 \%$ del total de ventas de alimentos debido a su alto coste.

En general, (Gade, 2008) la DO es la institución legal que existe entre consumidor y productor y fija la calidad singular del producto basada en el lugar ${ }^{10}$. Es el instrumento que permite al terroir, definido por fronteras, convertirse en espacio jurisdiccional. Fueron motivo de controversia en las negociaciones entre Estados Unidos y la Unión Europea, en el seno de la OMC (Barham, 2003). La UE reclamó la creación de un registro mundial de IG, y las corporaciones de los Estados Unidos se oponían a ello. En Europa las denominaciones pertenecen a la región misma y sólo puede ser administrada y regulada por el gobierno del Estado, que ha prevenido el fraude con certificados de inspección y otros mecanismos de control. Los productores no pueden producir fuera de la región y retener el nombre del lugar, a diferencia de una corporación que sí puede trasladar la producción y mantener la marca de mercado. Las Indicaciones Geográficas pertenecen al lugar (una forma de propiedad intelectual colectiva), en un contexto de globalización, contradictorio con la libertad de circulación de productos, personas y capitales.

\subsection{La delimitación de las DO, factores naturales, otras variables}

Desde 1996, existe en el seno de la Comisión de Viticultura de la Organización internacional del Vino un grupo de estudio sobre métodos para la delimitación de áreas vitícolas. Desde entonces se ha reunido en varias ocasiones, lo que pone de manifiesto la preocupación que genera la delimitación de áreas de producción singulares. En Francia, desde la promulgación de la ley que regula las DO de 1990, se impusieron métodos científicos puros (Fanet, 2007) y se realizaron ejercicios de delimitación del terroir a partir de datos geológicos. En ese contexto se produjo de nuevo la confrontación entre quienes invocan criterios técnicos, definiendo el terroir a partir del tipo

10 En España, la legislación contempla una IG, incluso más restrictiva que la DO, los vinos de pago. En Castilla-La Mancha, desde el año 2002 se han creado 8 vinos de Pago, donde destaca el de Valdepusa, en el municipio de Malpica de Tajo. Fue una finca pionera en España al introducir variedades como Syrah, Chardonnay y Cabernet Sauvignon de la mano de su propietario, Carlos Falcó, Marqués de Griñón. Los criterios empleados para su reconocimiento administrativo manifiestan, por si mismos, tendencias post-productivistas al especificar los métodos y técnicas empleados en el proceso de elaboración y en la valoración de los condicionantes geográficos como factores determinantes en la personalidad de los vinos (Ruiz, 2013, p. 139). 
suelo y de sus características ambientales, y, por otra parte, quienes dan gran importancia a la historia y a la tradición ${ }^{11}$.

La Geografía ha jugado históricamente un papel importante en la delimitación del terroir. Inicialmente (Schirmer, 2011) se priorizó el peso de la Geografía física ${ }^{12}$. Actualmente, en los nuevos países productores se delimitan las áreas vitícolas con SIG y teledetección, y en Europa se imponen los criterios sociales y culturales. De esta forma vemos como la globalización, que cristaliza en los nuevos espacios vitícolas, estaría contribuyendo a la búsqueda de las especificidades en el Viejo Mundo.

En esta misma línea, el terroir ha sido definido como "...un espacio de producción organizado, estructurado por los hombres. Más allá de las ventajas comparativas naturales, económicas o políticas que han presidido su creación, la permanencia de grandes terroirs, Bordeaux, etc., es el producto de uno o varios grupos sociales..." (Hinnewinkel, 2007, p. 17) .Tiene componentes técnicos, económicos, culturales y sociales, y es una arma para la defensa del patrimonio colectivo, para el mantenimiento de los campos vivos y para la promoción del vino ${ }^{13}$.

\section{Objetivo, hipótesis, fuentes y metodología}

El trabajo tiene como objetivo observar la evolución más reciente de la viticultura de Mallorca haciendo hincapié en los cambios en el tipo de viticultura y en el modelo de producción seguido por la industria de transformación. El análisis lo hemos centrado durante el período que va desde 1990 hasta 2015, en la hipótesis que el sector vitivinícola muestra evidencias empíricas del tránsito post-productivista.

Para poder asumir el objetivo antes apuntado se ha recabado y elaborado la siguiente información:

a) Datos documentales y estadísticos de los informes oficiales que sobre la situación del sector elaboraban distintas instancias de la Administración Uunta Consultiva Agronómica, Consejo Económico Sindical Provincial). b) Elaboración de tablas, gráficos y mapas a partir de la información del Registro Vitícola de las islas Baleares (hasta 2012). Las variables que contempla

11 Insistiendo en esa controversia, Barham (2003) afirma que los factores naturales son los definitivos en la vinculación del producto con el terroir. Aun así, reconoce el peso adquirido por las variables humanas y el savoir faire, muy importantes en la delimitación de una nueva DO. Para ello, hay equipos de antropólogos que analizan la habilidad de los productores para acotar las áreas geográficas.

12 Huetz de Lemps (2000, p. 499) en un trabajo sobre las DO en Castilla y León, llega a la conclusión que "...La combinación de todos los elementes del medio natural se refieren a una definición de los terroirs vitícolas muy sutil y permiten a cada chateau, a cada bodega, afirmar su personalidad. Y es posible luego establecer una clasificación y una jerarquía de grandes reservas en el espacio y también en el tiempo, cada milésima conservando su especificidad...".

13 En un estudio del Priorat, a partir de encuestas, se concluye que el desarrollo de la DO Priorat es el eje de dinamización económica de esa comarca., a través del turismo cultural y gastronómico, actividades sujetas a una nueva demanda, ligadas a la conservación del medio ambiente rural y del paisaje (Armesto \& Gómez, 2006). 
dicho registro aparecen referenciadas por polígono y parcela catastral, lo que ha permitido la elaboración de cartografía sobre diversos aspectos analizados en el trabajo. Los mapas se han realizado con el programa Arcgis de cartografía automática. Éstos identifican las parcelas con presencia del cultivo, o las parcelas con viña de una determinada variedad., c) Datos documentales y estadísticos de las denominaciones de origen y otras indicaciones geográficas, su normativa y las bodegas que pertenecen a las mismas obtenidas de la página web del Institut de Qualitat Agroalimentària del Govern de les illes Balears ${ }^{14}$, o facilitadas por los servicios administrativos de dichos organismos, d) Tabulación de los datos de la encuesta a los productores de vino realizada durante 2014 y 2015. Fue una encuesta dirigida a la totalidad de las bodegas y se mandó por correo electrónico en dos ocasiones a cada uno de ellas. Respondieron un $72 \%$ de las industrias (40 respuestas de un total de 56). La encuesta reunía un total de 23 preguntas, con las que se ha obtenido información sobre la capacidad de las bodegas, año de creación, su desarrollo tecnológico, la superficie vitícola que gestiona directamente cada una de ellas, el peso de la uva propia y de la ajena (otros viticultores), la procedencia geográfica de la uva, el sistema de venta, el peso de la exportación, los países dónde se exporta, el futuro del sector, además del peso adquirido por las indicaciones geográficas protegidas. Esta información ha sido de gran valía para el análisis de los cambios tecnológicos experimentados en la industria del vino, sus nuevas orientaciones productivas, sus estrategias de mercado y su vocación exportadora.

\section{Características del tránsito post-productivista: viticultura, industria de transformación, paisaje e identidad}

\subsection{Evolución del cultivo de la vid y de la superficie vitícola en Mallorca (1990-2012)}

El subsector vitivinícola de Mallorca presentaba a finales de los años ochenta claros síntomas de esclerosis: estructuras agrarias inadecuadas y, sobre todo, estructuras de producción y redes de comercialización ineficientes para hacer frente a la competencia de los vinos peninsulares elaborados a menor coste. La situación, en general, como la de la agricultura mallorquina, fue terreno abonado para que se agudizase tras la integración del Estado español en la Unión Europea.

La política comunitaria estuvo marcada por el problema de la producción vinícola excedentaria, motivada en gran parte por la creciente disminución del consumo interior. Las normativas de la PAC en materia vitivinícola intentaron, por una parte, reducir la producción de vino de escasa calidad, primando el arranque de viñedo, y favorecer una producción de calidad, mediante planes de restructuración. A través de éstos se fomentó la consolidación de un subsector modernizado y cuya producción estuviese adaptada a un mercado cada vez más exigente.

14 Ver http://www.illesbalearsqualitat.es/iquafront/iqua?lang=es 
En un primer momento, el arranque del viñedo fue el objetivo que más caló entre los viticultores, al verse afectado el subsector por la problemática que padece la agricultura balear en general: escasa rentabilidad, escasa dedicación con un porcentaje alto de viticultores a tiempo parcial, envejecimiento de la población activa agraria, suspensión de pagos del Celler Cooperatiu. Desde 1986 hasta 1996, desaparecieron, acogiéndose a la prima por arranque, un total de 1091,25 ha y de 2074 parcelas. Fue en 1991 cuando se alcanzaron las mayores cifras, con 411 parcelas descepadas que se corresponden a 225,61 ha (Binimelis, 1999, p. 34). Aunque el arranque de la vid se concentró geográficamente en las áreas de mayor especialización vitícola de la Zona Alta y, sobre todo, de la Zona Baja (concretamente, las cifras más altas se dan en los predios de Son Nadal, Es Vinyet de sa Grava, Son Amer, Albocàsser y Justaní, entre los municipios de Felanitx y Manacor) también desaparecieron las parcelas de viñas marginales ubicadas en zonas de escaso peso. En definitiva, a principios de la década de los noventa, habían desaparecido muchas de las parcelas que configuraban un sistema agrario y un paisaje casi monocolor en amplias áreas agrícolas del sudeste de la isla.

Los planes de restructuración del viñedo, coetáneos durante algunos años con las subvenciones por arranque, catapultaron desde principios de los años noventa un nuevo modelo que representa un cambio substancial respecto al ciclo anterior. Si la Revolución Verde, con la mecanización de la viticultura y la introducción de procesos de elaboración de carácter industrial en los cellers, introdujo escasos cambios en el paisaje vitícola que se consolida tras la superación de la crisis de la filoxera en los años veinte del siglo pasado, el desarrollo de la viticultura auspiciada por los planes de restructuración ha representado una transformación sustancial.

Según datos del Registro Vitícola de las Illes Balears, había en 2012 un total de 1802,91 ha de viña en 2764 parcelas. Desde 1991 hasta 2012, se han plantado 1092,13 ha en 1338 parcelas. Teniendo en cuenta que la vida productiva de la viña en Baleares es de 30-40 años, podemos afirmar que el 60,6\% de la actual superficie vitícola es de nueva creación, caracterizando claramente un período de acentuado crecimiento del número de hectáreas. Esta nueva etapa de crecimiento de la superficie vitícola es contemporánea con la segunda globalización del sector vitícola (Pan-Montojo, 2009, p. 4). Subsisten 58,14 ha y 198 parcelas plantadas antes de 1960, mientras que 369,03 ha y 854 parcelas lo hicieron entre 1961 y 1980 y 179,52 ha y 195 parcelas datan del período que va de 1981 hasta 1990 (Figura 1). 
Figura 1. Superficie y parcelas de viña existente en Baleares según año de plantación (2012) ${ }^{15}$

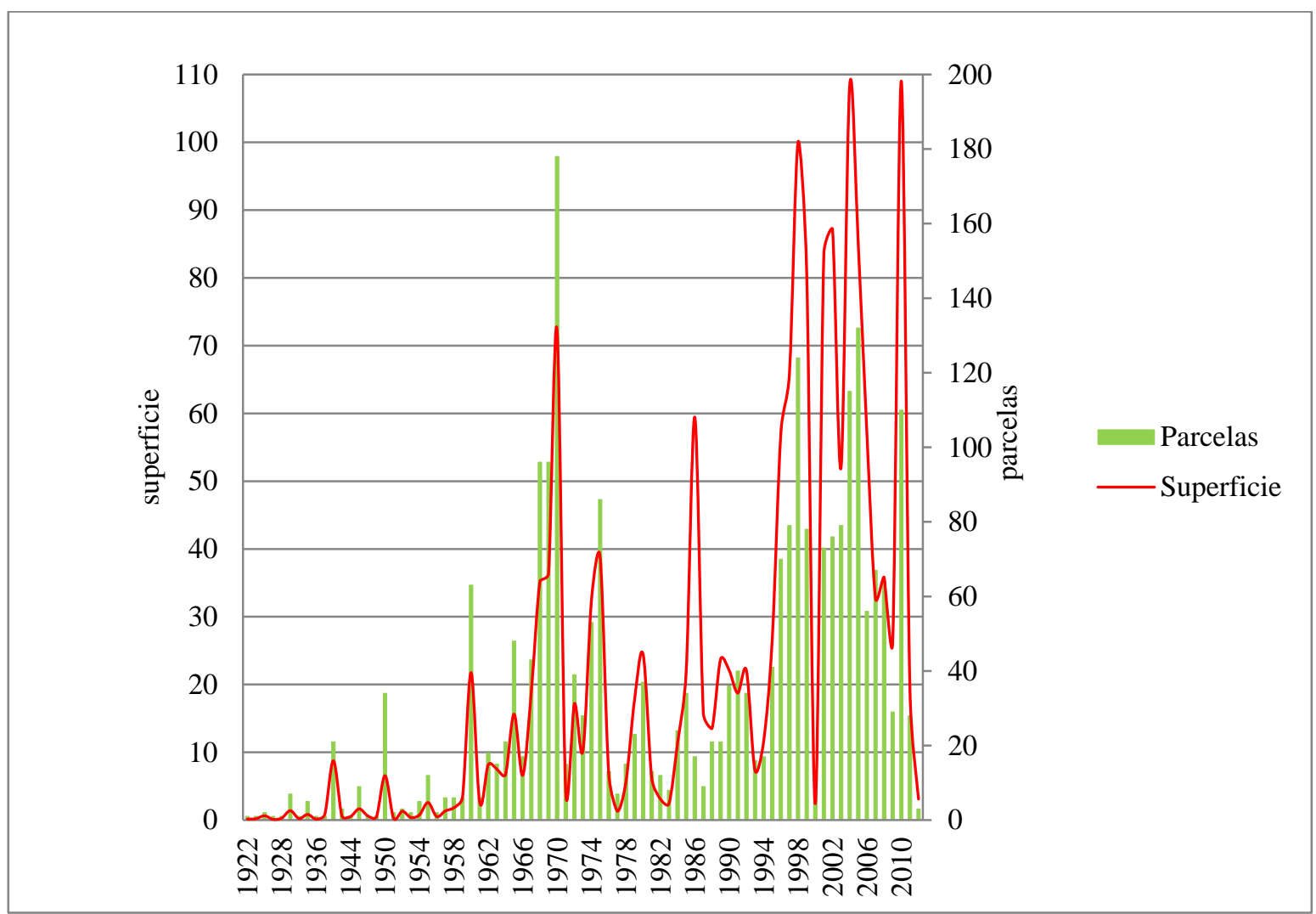

Fuente: elaboración propia a partir de datos de 2012 del Registro Vitícola de las Illes Balears

En la actualidad la distribución del cultivo de la vid se caracteriza por su dispersión geográfica (Figura 2). Aunque la viña sigue teniendo importancia en aquellos municipios de tradición secular que capitalizan la labor de la dos DO existentes: Santa Maria (196 ha), Consell (87,7 ha), Binissalem $(214,3$ ha) y Sencelles $(170,2)$ en la DO Binissalem; y Manacor $(174$ ha), Porreres $(82,5$ ha) y Felanitx (186,4 ha) en la DO Pla y Llevant. No obstante, las actuales pautas de distribución muestran dos variantes en relación a la etapa anterior: a) hay una mayor concentración de viñas en los municipios de la DO de Binissalem (antigua Zona Alta); y b) se produce una dispersión geográfica del cultivo, siendo pocos los municipios de la isla sin algunas parcelas de viña, reapareciendo en municipios de la Serra de Tramuntana como Estellencs y Banyalbufar, a remolque de la romántica iniciativa de recuperación de la variedad malvasía, glosada por el Archiduque Luís Salvador. O también en Escorca y Pollença, Puigpunyent y Andratx. La dispersión geográfica de la vid sólo excluía 13 municipios (Valldemossa, Bunyola, Deià, Sóller, Fornalutx, Lloseta, Campanet, sa Pobla, Ariany, Villafranca, Costitx, Son Servera y Ses Salines) debido a la eclosión de nuevas iniciativas encaminadas a la producción de vino a pequeña escala, pequeñas bodegas de producción artesanal y personalizada.

15 En el gráfico la superficie, en línea roja, se mide en el eje de la izquierda. Mientras que las parcelas, en una columna verde, se contabilizan en el eje de la derecha 
Figura 2. Mapa de las parcelas ocupadas por viñedo en 2012

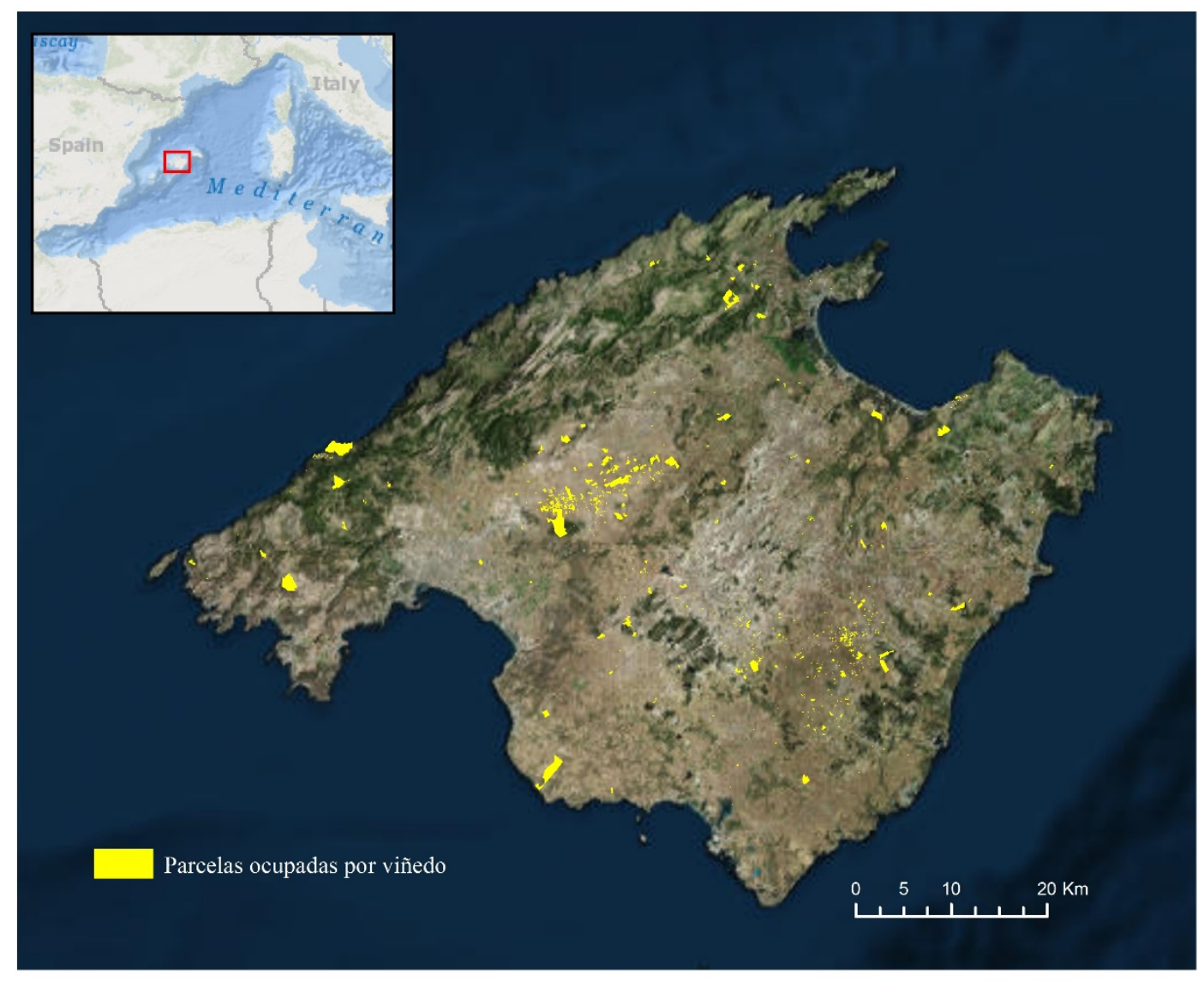

Fuente: elaboración propia a partir de datos de 2012 del Registro Vitícola de las illes Balears

\subsection{Atomización de la industria de transformación}

La actual distribución del cultivo de la viña responde, en buena medida, al desarrollo atomizado de una nueva industria de transformación, formada en gran parte por pequeñas bodegas, de escasa capacidad, que cuenta con sus propios viñedos a la manera de los chateaux franceses. Los nuevos y numerosos cellers, conviven con algunas firmas antiguas, que ya existían durante las décadas de dominio del paradigma industrial. Estas bodegas tradicionales son, en general, las de mayor capacidad y su existencia, ya desde inicios del pasado siglo, permitió la consolidación de un modelo de distribución territorial donde se produjo la concentración de la superficie vitícola en torno a las grandes industrias de transformación. Regresamos, pues, a pautas más antiguas, donde la concentración y especialización conviven con la dispersión geográfica del cultivo.

La atomización de la industria responde al cambio en los hábitos de consumo que han tenido lugar desde los años ochenta. Desde entonces, disminuyó el consumo de vino per cápita, sobre todo en los grandes países productores (Unwin, 2001) cuando se convierte en bebida ligada al disfrute 
personal $^{16}$. Por tanto, se produce un tránsito desde un producto pensado para una demanda masificada que ofrecía el mercado turístico a una demanda elitista con gusto por la calidad y por el producto diferenciado. Ello ha comportado, sin duda, una clara segmentación de la demanda. Además, el cambio tecnológico que ha tenido lugar en el ámbito de las bodegas -depósitos de acero inoxidable, sistemas de refrigeración, nuevas tecnologías- ha facilitado la proliferación de unidades de producción artesanal.

La industria que se ha desarrollado al amparo de los planes de reestructuración se organiza bajo la protección de una complicada trama de indicaciones geográficas: la DO de Binissalem, DO del Pla y Llevant, IGP Vi de la Terra de Mallorca, la IGP Costa Nord y IGP Vi de la Terra illes Balears ${ }^{17}$.

En Mallorca había 56 bodegas en el año 2015, inscritas todas ellas en alguna de las indicaciones geográficas existentes. La Denominación de Origen Pla i Llevant contaba con un total de 13 bodegas, la DO de Binissalem con 14 y la IGP Mallorca era la mayoritaria con 43. Sin embargo, hay 6 cellers de la DO Binissalem y 3 de la DO Pla y Llevant que, a su vez, pertenecen a la IGP Mallorca. Por último, la IGP Costa Nord, agrupa a 3 industrias de Banyalbufar y Estellencs dedicados a la producción de vino blanco de malvasía y la IGP illes Balears cuenta con una sola bodega en Mallorca. Una parte significativa de los cellers de las dos DO, pertenecen también a la IGP Mallorca, sobre todo las de Binissalem. Es esa una forma de evitar las normas más rígidas sobre las características del vino, rendimientos permitidos y las variedades utilizada. Además, la compartimentación de la producción entre IGP y DO permite comprar cosecha de uva en cualquier lugar de la isla. La IGP Mallorca, siendo una indicación geográfica, es una válvula de escape para las industrias de mayor capacidad, más preocupadas en satisfacer la demanda que en la construcción de una imagen propia. La construcción de la identidad, apelando al pasado denota la necesidad de construir un relato, un discurso, aunque éste no se ajuste después a la realidad ${ }^{18}$.

La capacidad de las bodegas desvela la dispersión de la producción. En la encuesta dirigida a la industria (respondieron el $72 \%$ del total de bodegas existentes en el mes de marzo de 2015) un $80,5 \%$ de los cellers tienen una capacidad inferior a los 2000 hl y sólo un 19,5\% tienen una capacidad superior. En este tramo, algunas incluso se sitúan por encima de los 15000 hl (Tabla 1). Por otra parte, las bodegas, en general, hacen un buen uso de su capacidad. El $67 \%$ (27

16 En las últimas décadas del siglo XX “... España se insertó en el mercado internacional del vino a través del modelo de vinos con denominación de origen o marcas geográficas..." (Fernández, 2012, p. 71), siguiendo del modelo francés. Ésta ha sido la estrategia productiva y comercial del Viejo Mundo para hacer frente a la eclosión de los nuevos países productores, en la etapa de la segunda globalización del vino (Pan-Montojo, 2009)

17 La información sobre denominaciones de origen y otras indicaciones geográficas ha sido tomada de la página web del Institut de Qualitat agroalimentària de les illes Balears. Conselleria d'Agricultura, Medi Ambient i Territori. Denominacions i Marques. Retrieved from http://www.illesbalearsqualitat.es/ibafront/iqua

18 Véase al respecto, los decretos reguladores de la DO Binissalem, DO Pla y Llevant, IGP Mallorca o IGP Costa Nord-Serra de Tramuntana. Ver http://www. illesbalearsqualitat.es/iquafront/iqua?lang=es 
bodegas) utiliza más del $60 \%$ de la misma. Solo un $25 \%$ (10 bodegas) manifiesta una utilización inferior al $60 \%$, que en muchas ocasiones se explica por su juventud y por disponer de un viñedo en buena parte no productivo.

Figura 3. Ca'n Sureda Ric, Manacor. El nuevo modelo ha impregnado la isla de industrias artesanales, tecnificadas, de baja producción y que se alimentan de la uva de sus propios viñedos

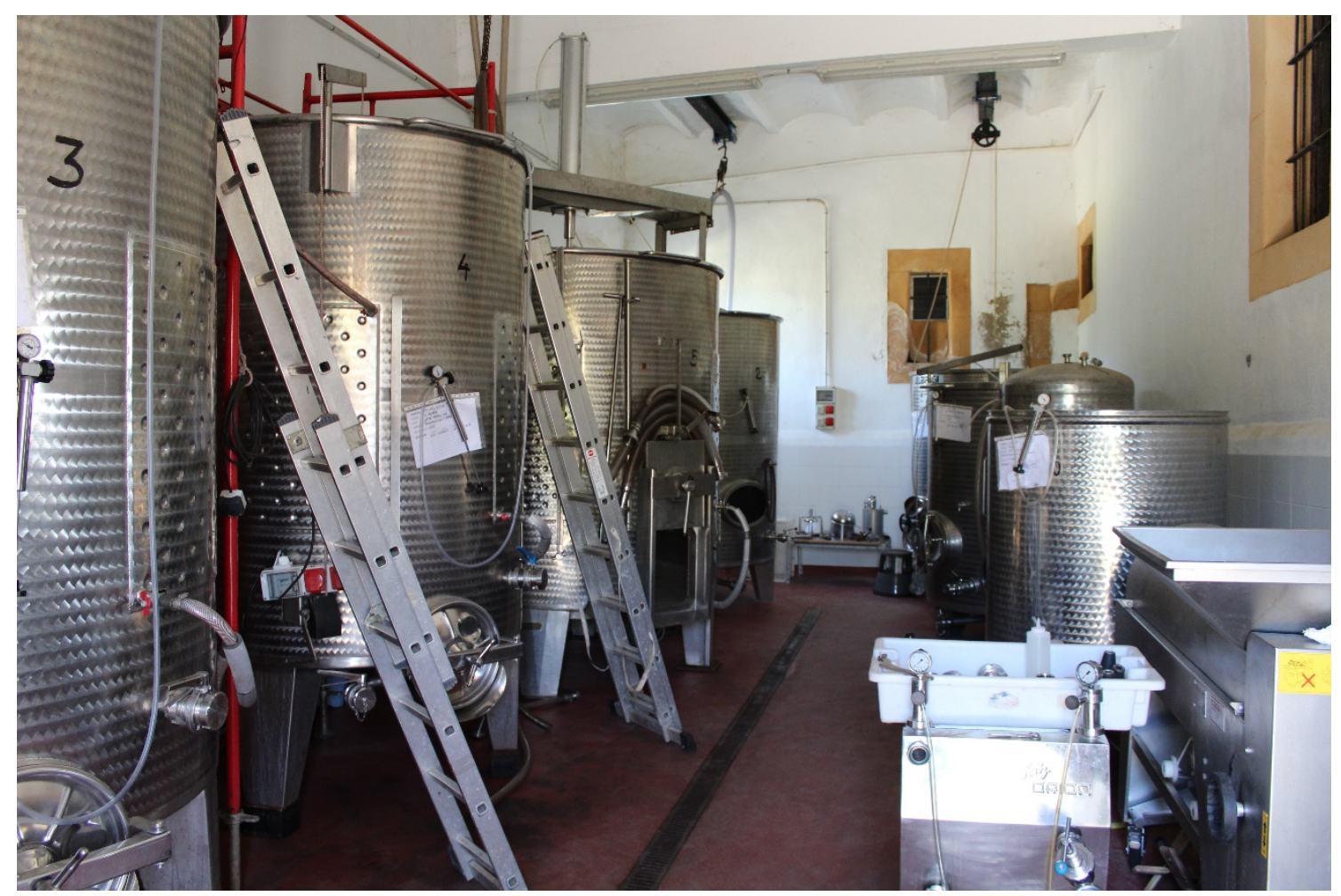

Fuente: elaboración propia

Tabla 1. Capacidad de las bodegas

\begin{tabular}{|l|c|c|}
\hline Menos de $200 \mathrm{HI}$ & 9 & $22,50 \%$ \\
\hline Entre 201 y $500 \mathrm{HI}$ & 7 & $17,50 \%$ \\
\hline Entre 501 y $1000 \mathrm{HI}$ & 5 & $12,50 \%$ \\
\hline Entre 1000 y $2000 \mathrm{HI}$ & 11 & $27,50 \%$ \\
\hline Entre 2001 y $5000 \mathrm{HI}$ & 5 & $12,50 \%$ \\
\hline Más de $5000 \mathrm{HI}$ & 3 & $7,50 \%$ \\
\hline TOTAL & 40 & $100,00 \%$ \\
\hline
\end{tabular}

Fuente: elaboración propia a partir de datos de la encuesta

a los productores de vino realizada durante 2014 y 2015

Además, existe una relación entre el año de creación de la industria y su capacidad. Las bodegas ya existentes en la etapa industrial de la viticultura isleña tienen capacidades altas y media-altas. Mientras que, las de nueva creación se caracterizan por una capacidad de producción baja o muy 
baja (Tabla 2, Figura 3 y Figura 4). Son esas bodegas de producciones artesanales las que han creado un tejido industrial disperso en clara consonancia con las características propias del paradigma post-productivista.

Figura 4. Relación entre capacidad de las bodegas y año de creación

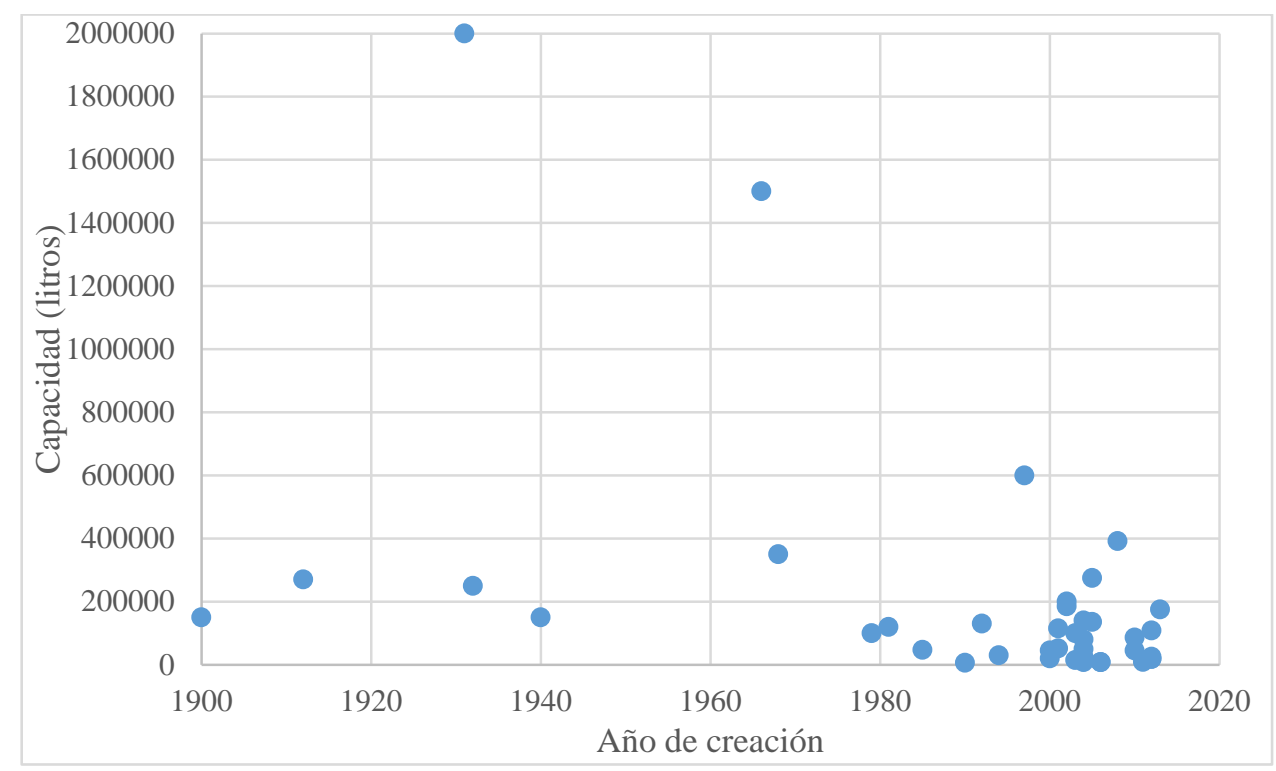

Fuente: elaboración propia a partir de datos de la encuesta

a los productores de vino realizada durante 2014 y 2015

Tabla 2. Año de creación de las bodegas

\begin{tabular}{|l|c|c|}
\hline Antes de 1990 & 11 & $27,50 \%$ \\
\hline Entre 1991 y 2000 & 5 & $12,50 \%$ \\
\hline Despúes de 2000 & 24 & $60,00 \%$ \\
\hline TOTAL & 40 & $100,00 \%$ \\
\hline
\end{tabular}

Fuente: elaboración propia a partir de datos de la encuesta

a los productores de vino realizada durante 2014 y 2015

Las bodegas, en el nuevo paradigma, se alimentan, en buena parte, de la cosecha de sus propios viñedos, al contrario de lo característico del modelo industrial, de la etapa anterior, que se caracterizaba por la separación entre la esfera de la producción de uva, de su industria de transformación (Figura 5). Ahora, las pequeñas bodegas producen los vinos de sus propios viñedos, claro reflejo de la búsqueda de marca propia. De hecho, un $68 \%$ de las bodegas que respondieron a estas cuestiones se nutren con más del $75 \%$ de uva propia. Son, las bodegas de dimensiones medias y altas, que han sobrevivido a la etapa industrial, las que se alimentan en gran parte, de la producción de uva ajena. No obstante, también éstas han invertido en la plantación de viñas y, por tanto, han apostado por la producción propia. La figura del viticultor, antes dominante, ahora está en franco retroceso, y es el bodeguero-viticultor lo que caracteriza el nuevo modelo. 
Figura 5. Relación entre cantidad media de uva utilizada en cada cosecha y porcentaje de uva comprada

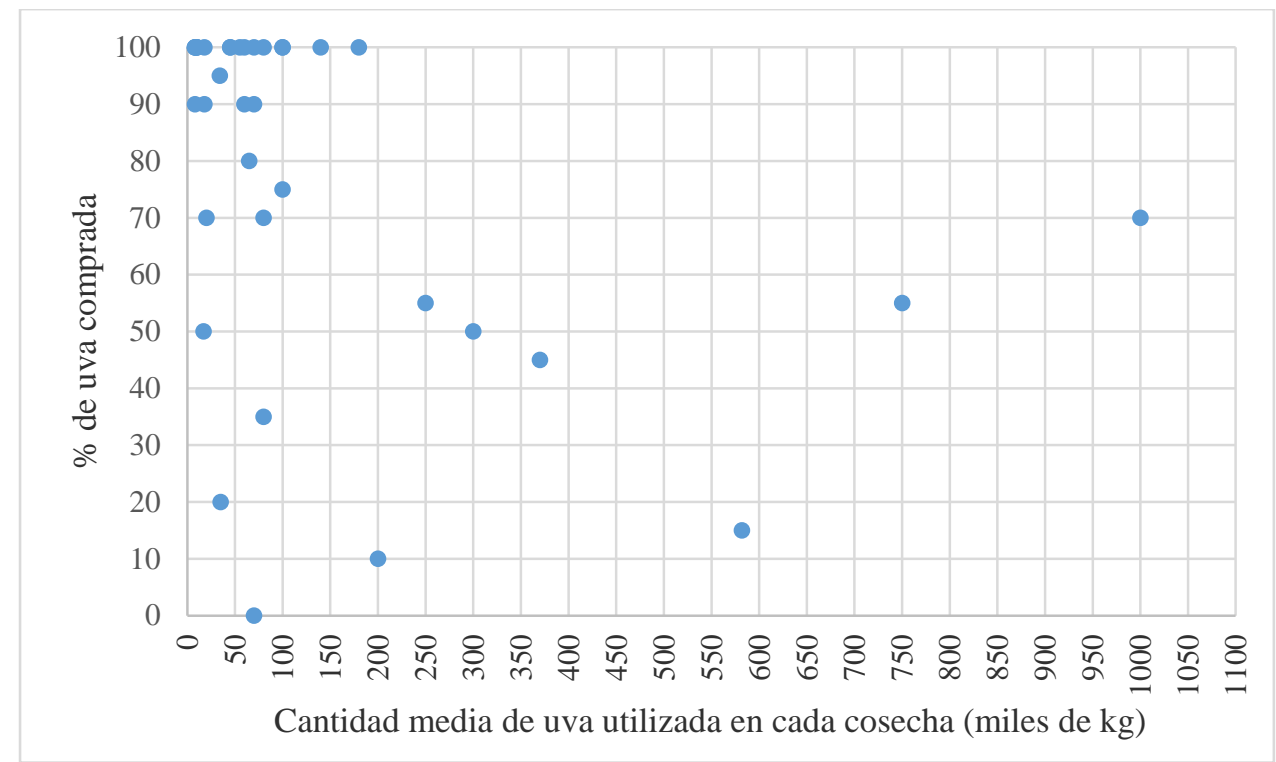

Fuente: elaboración propia a partir de datos de la encuesta

a los productores de vino realizada durante 2014 y 2015

Sin embargo, el origen de la uva nos muestra la pervivencia de la figura del viticultor en aquellos municipios que concentraron la producción de esta actividad en el pasado siglo como son Sencelles (aparece en 8 respuestas), Felanitx (7 respuestas), Binissalem (6 respuestas), Santa María (5 respuestas), Manacor (5 respuestas), Consell (4 respuestas) y Porreres (2 respuestas). El resto de municipios señalados (Llucmajor, Maria de la Salut, Alaró, Artà, Santa Eugènia, Banyalbufar, Montuïri e Inca), aparecen en una sola ocasión.

También ha habido cambios sustanciales en la comercialización y distribución del producto final. Como media (han respondido a esta cuestión 37 de las 40 bodegas estudiadas) las industrias isleñas venden en bodega un 21 por ciento de su producción. Su red de distribución propia (clientes propios) representa un $15 \%$. No obstante, la fórmula mayoritaria de venta es a través de distribuidores con un 42,4\%. La exportación de vino tiene un peso creciente, con un $21,4 \%$. Por último, la venta online tiene todavía escasa importancia, con una media del 0,2\%. No obstante, se observan dos modelos de bodega. En primer lugar, hay 6 bodegas que exportan más del $50 \%$ de su producción al extranjero. Mientras, el resto dedica sus esfuerzos a atender el mercado regional y turístico, sin descartar, en algunos casos la venta al extranjero. En este grupo, hay 18 bodegas que venden a través de distribuidores en el mercado regional más del 50 \% de su producción. También hay un grupo minoritario de 4 bodegas, de producción artesanal muy reducida, que comercializan en bodega el $80 \%$ de su producción. Y otras 8 bodegas venden buena parte de su producción (más del $40 \%$ ) desde su propia red de distribución. 
La distribución y comercialización es, en conclusión, una característica distintiva de esta nueva etapa con la creciente importancia de la exportación de los caldos. En este sentido los países de destino, según las respuestas obtenidas, son principalmente: Alemania, Suiza, Dinamarca, Estados Unidos, Austria, Suecia, Bélgica, Holanda. En segundo lugar, también se cita a Japón, Reino Unido, China y Puerto Rico. Por tanto, un abanico de países que va más allá de los límites de la Unión Europea ${ }^{19}$ siendo, por tanto, el vino mallorquín, un producto local con proyección global.

\subsection{Viticultura y paisaje. Posibles repercusiones paisajísticas de la nueva viticultura insular}

Desde los años sesenta, la mecanización de las tareas culturales contribuyó al aumento de los rendimientos, aunque introdujo escasos cambios en la configuración del paisaje vitícola. A finales de los años cincuenta desde la Administración aún se discutían las ventajas e inconvenientes de dos método de preparación de los terrenos, gavetes (zanjas hechas a mano con azadas) o desfonde ${ }^{20}$. La gaveta resultaba más cara, (6000 pesetas/ha) frente al desfonde con tractor (4261 pts./ha) y con una relación de metros cúbicos removidos por planta inferior: 0,355 $\mathrm{m}^{3} /$ planta en el sistema de zanjas frente a 2,03 $\mathrm{m}^{3} /$ planta en desfonde (Consejo Económico Sindical Provincial de Baleares, 1959, p. 68).

Esos mismos informes recomendaban, para el uso del tractor, el marco de plantación de 2,4 m por $1,2 \mathrm{~m}$

(...) La distancia de 2,40 entre líneas permite el paso de un tractor corriente de hasta 45 HP para las dos labores de vertedera y 3, hasta 4, labores de cultivador, siempre que se cuide de conducir la vegetación de cada cepa sobre las vecinas a 1,20, con lo cual queda muy despejado el terreno de la calle. Sólo el hecho de pensar que un tractor pueda labrar con vertedera de 6 a 8 cuarteradas en una jornada normal, dará toda la importancia que deberá tener la mecanización del viñedo tan falto hoy en día de mano de obra (...) (Consejo Económico Sindical Provincial de Baleares, 1959, p. 68)

19 En el caso de la bodega Anima Negra Viticultors nos informaron que exportan a 34 países.

20 Ya desde los años cuarenta, se reclamaba la necesidad de introducir arados de desfonde, cambio técnico necesario en las labores de preparación, con el objetivo de abaratar los costes de plantación: "... conviene abaratar el coste de plantación, muy caro en las circunstancias presentes, para ello convendría que en forma Sindical se adquirieran un par de trenes de desfonde..." (Anteproyecto de ordenación económico-social de Baleares 19471951, 1947, p. 194). No obstante, el uso de arados de desfonde es considerado una de las causas del aumento de la productividad de la nueva viticultura que surge tras la filoxera: "...desde un primer momento de la necesidad de arar profundamente la tierra antes de plantar las nuevas cepas, ya que dicha operación permitía un crecimiento más rápido de las nuevas plantas y, a la vez, aumentaba su resistencia y productividad..." (Colomé, 2001, p. 56). Sin embargo, frente al retardo experimentado en Mallorca en relación a este cambio técnico, sí se difundieron equipos de desfonde en otras regiones vitícolas peninsulares desde finales del siglo XIX en Aragón: "... difundidos desde Aragón hasta Valencia en la década de 1890, tuvo que ser la propia Administración, por medio de las estaciones enológicas... los que compraran las primeras máquinas..." (Sabio Alcutén, 2001, p. 219) y en Requena: "...A finales del siglo XIX se dieron a conocer los grandes arados de desfonde o malacates, tirados por un largo cable que se enrollaba en una especie de torno o rueda que se fijaba en un extremo del campo y era movida por cuatro o más caballerías..." (Piqueras, 2001, p. 125). 
Pero esas facilidades no solamente se manifiestan en las labores de cultivo, sino también en los tratamientos anti-criptogámicos:

Otra ventaja que representa la indicada disposición es la que se refiere a los necesarios tratamientos anti criptogámicos, puesto que permite la entrada de recipientes transportados por tractor o caballerías.., de suficiente capacidad y potencia, que permiten tratar rápidamente una extensión muy superior al sistema de mochila o manual (...) (Consejo Económico Sindical Provincial de Baleares, 1959, p. 68)

Desde las instancias oficiales se apostaba por una nueva viticultura, mecanizada y que abandonasen las formas tradicionales de trabajar las viñas la pesar de la persistencia de las caballerías a principios de los sesenta). En esa nueva apuesta se pretendía homogeneizar el marco de plantación, un sistema de líneas de calles anchas. En realidad, la mecanización supuso una ligera modificación de los marcos de plantación que se adaptaron al tractor. No obstante, persistieron las diferencias locales entre la Zona Baja (sistema de líneas) y la Zona Alta (marco real). En la zona del Raiguer, el marco real de 7 palmos, se transformó en un marco de 9 o 10 palmos por banda. Son cambios, éstos, que poco influyeron en la fisonomía de los paisajes vitícolas.

La arada amb pala, fue sustituida por los arados viñeros con los que se podía trabajar la viña en primavera, descalzando y aporcando la tierra con las vertederas tras la poda y en los meses de primavera. En verano, se sustituían las vertederas por los cultivadores en el chasis del arado, para labores superficiales. Por otra parte, los arados de recórrer tirados por caballerizas fueron sustituidos paulatinamente por arados inter-cepas (a partir de los años ochenta del siglo pasado), complemento de los arados viñeros. Las nuevas herramientas (arado viñero y arado inter-cepas) adaptadas a la nueva fuerza motriz, el tractor, reproducían el mismo sistema de cultivo de la viña que se venía utilizando desde siempre: tres labores de vertedera, descalzando y calzando por dos veces y varias labores de cultivador en verano. Asimismo, las bombas para tratamiento anticriptogámico movidas por las cardan del tractor, sustituyeron las bombas de pistón que aprovechaban el traqueteo del carro movido por caballerizas. Asistimos, por tanto, durante las décadas de los sesenta hasta finales de los ochenta, a la paulatina sustitución de herramientas de gestión vitícola tradicionales, que definieron un modelo de agricultura a caballo entre el modelo orgánico y el industrial. En ese tránsito, la viticultura pasa a ser completamente dependiente desde el punto de vista energético, a pesar de la importante proporción de los ínputs de trabajo en determinadas fases del proceso de producción.

Ya a principios de los años noventa, los planes de reestructuración, que coexistieron durante un lustro con las ayudas al arranque del viñedo obsoleto, marcaron el despegue de una nueva fase expansiva que llega hasta la actualidad. La nueva viticultura ha rediseñado por completo el sistema de cultivo. Los arados viñeros fabricados por encargo en talleres y herrerías locales, han sido 
suplantados por cultivadores de diseño fabril y realizado en serie por la industria de maquinaria agrícola española y extranjera. Las labores de cultivo ya no se llevan a cabo con los, ahora obsoletos, arados viñeros. Actualmente las labores de cultivo se realizan con bastidores de los que cuelgan extirpadores o cultivadores, de brazos fijos o móviles, con accionamiento hidráulico que los estrecha o ensancha, en función de la anchura de calle. Los inter-cepas hidráulicos con palpadores electrónicos extremadamente sensibles han sustituido a los viejos arados inter-cepas mecánicos. Además, la escarda mecánica ha dado lugar a la escarda química, debido a la eficacia de los herbicidas sistémicos. Los pulverizadores han dado paso a atomizadores cada vez más eficientes en el ahorro de agua y distribución homogénea de los productos anti-criptogámicos. Las grandes bodegas han eliminado la vendimia manual tras la adquisición de vendimiadoras mecánicas. Aunque no de forma generalizada, también han hecho su aparición las pre-podadoras y las despuntadoras mecánicas, automatizando tareas que hasta el momento se realizaba de forma manual. Incluso en las labores de poda se han producido mejoras, pues han aparecido las tijeras de poda eléctricas que facilitan y aceleran el ritmo del trabajo. Para todo ello, en general, ha sido necesaria la aparición de tractores de mayor potencia (de 60 a 90 caballos) y doble tracción.

La creciente automatización de las labores en el viñedo ha venido acompañada de un cambio en el sistema de formación y en el marco de plantación. La viña en vaso, baja (35-40cm, la altura de las tijeras de poda, según dicta la tradición), casi ha desaparecido a favor de la viña alta (60$80 \mathrm{~cm}$ ) con sistema de doble cordón, con un marco de plantación casi estandarizado de 2,4 m x 1,20 m. El nuevo sistema de formación favorece la insolación de la uva, contribuye a la calidad del producto y facilita, bajo los parámetros de la automatización, las labores de cultivo, los tratamientos fitosanitarios y la vendimia mecanizada. Otra novedad introducida en las nuevas viñas ha sido el uso de irrigación por goteo, innovación tecnológica que no ha tenido, sin embargo, una aceptación generalizada. El desarrollo de la viticultura en espaldera, casi siempre asociada a la automatización de las labores y a la implementación del viñedo en regadío, tiene importantes consecuencias paisajísticas y también ambientales, claramente evidentes en áreas de especialización vitícola como Castilla-La Mancha (Ruiz Pulpón, 2013, p. 260)

Las diferencias comarcales en sistemas de formación y de cultivo entre la zona Alta (casi coincidente con la DO de Binissalem) y la Zona Baja (que incluye el núcleo central del área vitícola de la DO Pla y Llevant) han, prácticamente, desaparecido. La nueva viticultura ha impuesto un marco de plantación de calles anchas y el doble cordón como sistema de formación, que da paso a una viña alta, en espaldera, que facilita la automatización de las labores y crea paisajes homogéneos, estandarizados, sin las diferencias locales que respondían a razones culturales seculares (Figura 6). 
Figura 6. Viñedo de Miquel Oliver (Petra). El viñedo en espaldera, uno de los iconos del nuevo modelo, ha contribuido a un cambio fisionómico del paisaje vitícola

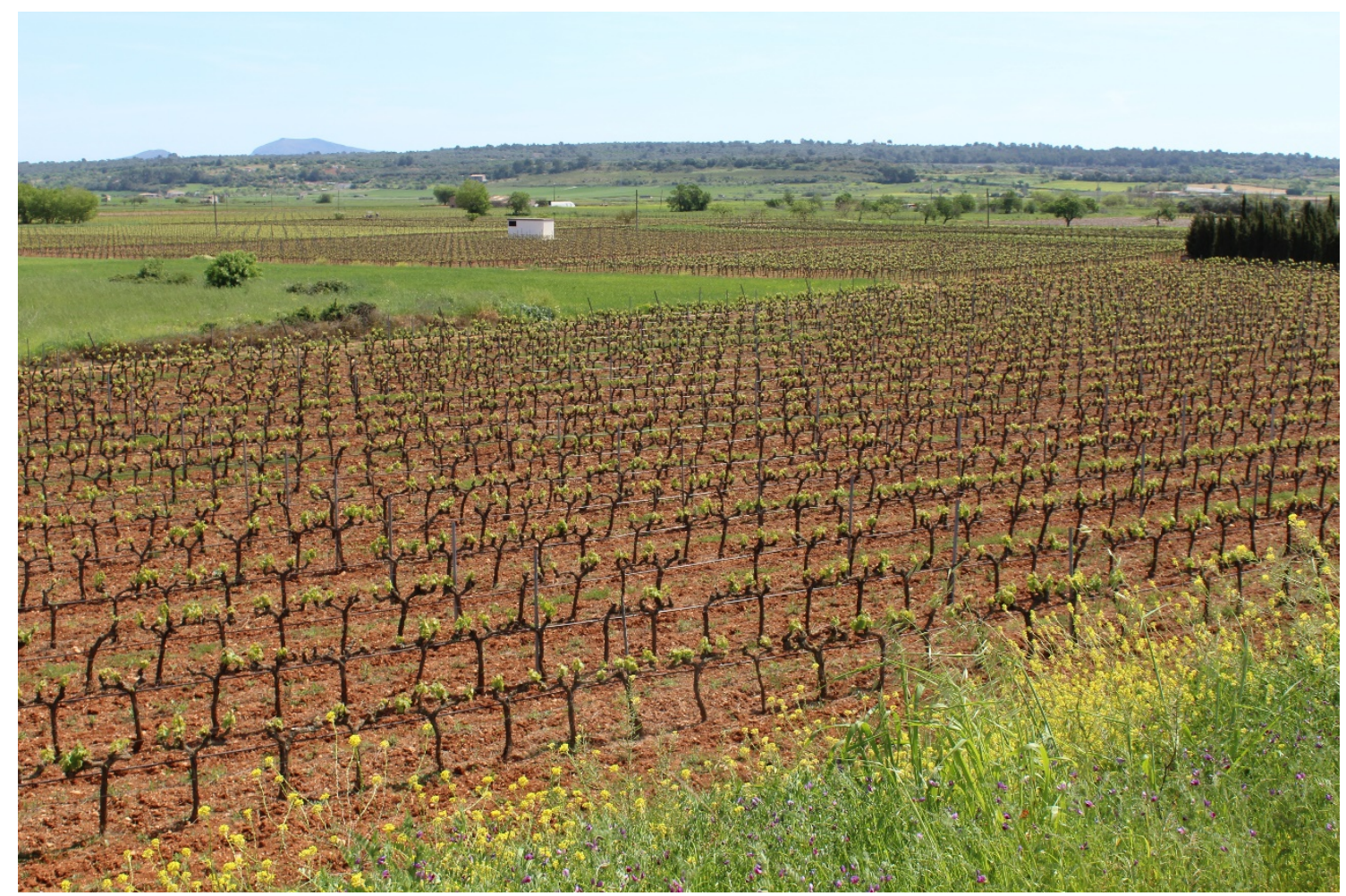

Fuente: elaboración propia

No obstante, frente a la creciente motorización de la nueva viticultura, existen productores que apuestan por la gestión ecológica del cultivo para la producción de vino de alta calidad. Estos defienden, entre otras, la vendimia manual, una ejecución de la poda ligada a las fases lunares (Lluna vella para enraizar y Lluna nova para adquirir vigor), la sustitución de la escarda química por la escarda mecánica a través del arado inter-cepas para evitar la proliferación de malas hierbas y potenciar el enraizamiento profundo de la planta, el uso de materia orgánica casi como único fertilizante (siembra y desbroce de leguminosas en las calles, uso de los sarmientos como materia orgánica), la gestión de la humedad del suelo desde la labor cultural. Incluso, algunas bodegas apuestan por no cultivar las viñas como forma de gestión. Esta filosofía de producción, en la que se hallan inmersas unas pocas bodegas y unos pocos viticultores, defiende la producción casi en exclusiva con variedades autóctonas y reivindica la recuperación de las variedades denominadas pre-filoxéricas. Incluso, algunos han retomado las labores con la tracción animal, para evitar la huella de labor de tractores y otra maquinaria autopropulsada (Figura 7). Además, en su credo figura la conservación y restauración de las antiguas parcelas de viña en vaso y se realizan nuevas plantaciones con sistemas de formación y de plantación a la antigua usanza. 
Figura 7. Labores de cultivo entre cepas con par de mulos. La tracción animal es reivindicada por la viticultura biodinámica, opción minoritaria entre los sistemas alternativos de cultivo usados por los bodegueros en Mallorca

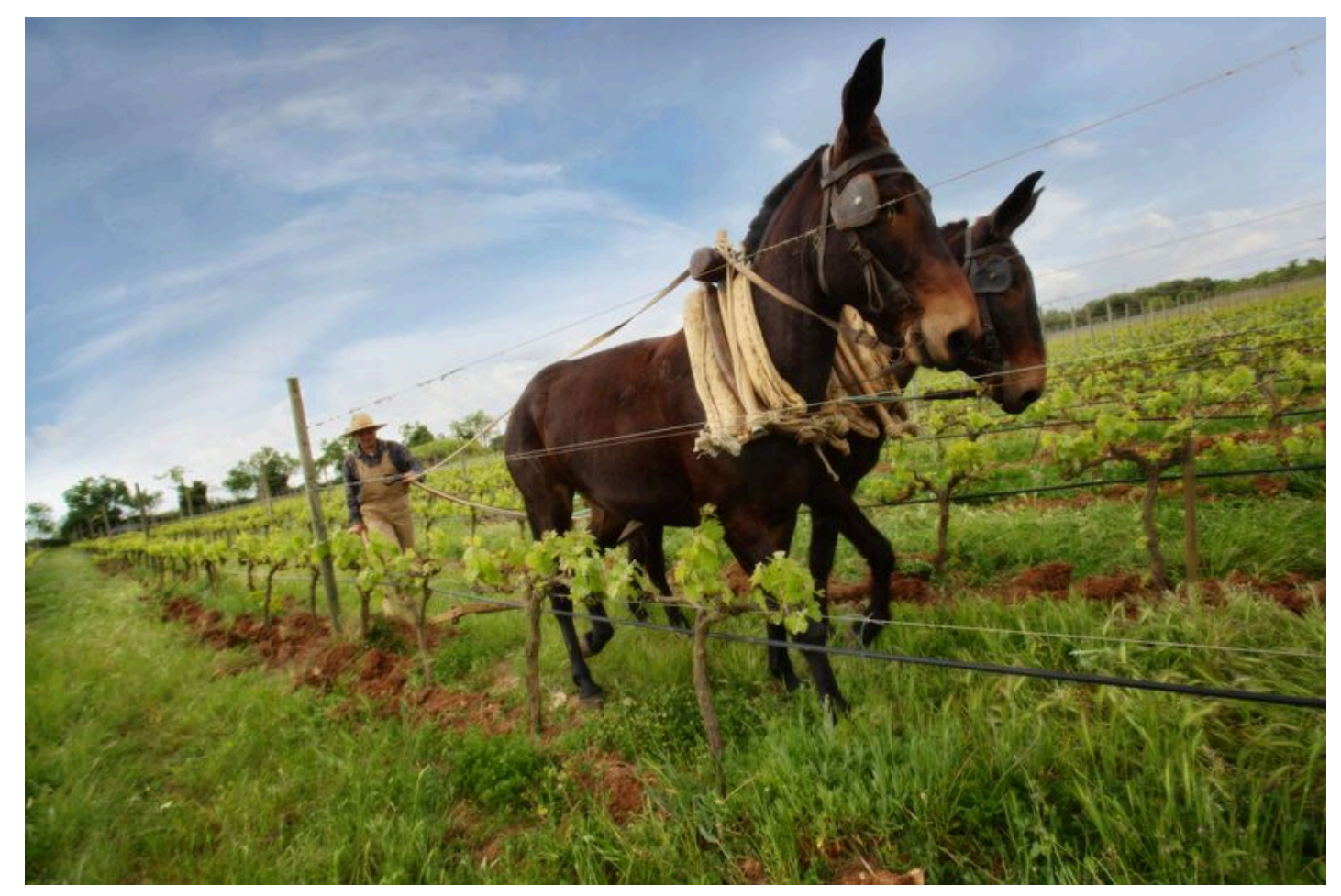

Fuente: Bàrbara Mesquida (2014)

La viticultura ecológica ha crecido al ritmo del crecimiento de la nueva viticultura. La superficie vitícola gestionada con el sello ecológico ha pasado de 0,4 ha en 1991 a 395,3 ha en 2012 para el conjunto insular lo que representa un $22 \%$ del total (Figura 8).

Figura 8. Evolución de la superficie de viñedo ecológico en Mallorca y Baleares

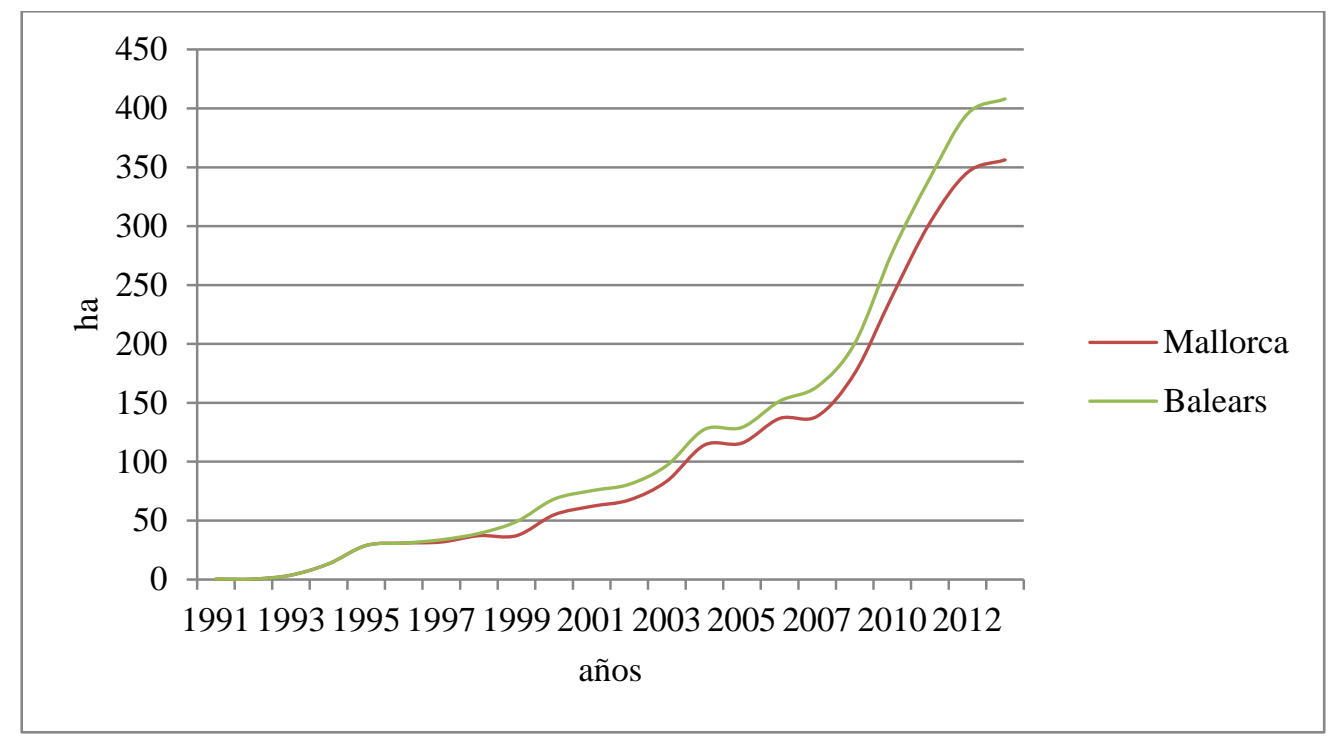

Fuente: elaboración propia a partir de datos cedidos por el Consell Balear de la Producció Agrària Ecològica (2012) 
La viticultura ecológica se asemeja en su praxis a la viticultura tradicional. La normativa permite el uso del cobre (sulfato de cobre, dióxido de cobre, caldo bordelés, etc.) y del azufre como fungicidas con los que atacar el mildiu y el oídium, los dos principales peligros que acechan cada año al viñedo insular. Por otra parte, prohíbe el uso de herbicidas y el control de las plagas de insectos debe de abordarse con el uso de insecticidas naturales como son el aceite de neem o las piretrinas naturales. El retorno a las esencias de la viticultura tradicional y a las prácticas que daban identidad está en la filosofía y forma de gestión de los nuevos viticultores ecológicos.

En definitiva, la nueva viticultura se ha desarrollado al tiempo que desaparecían las viejas parcelas de viña en vaso, consolidando un modelo dependiente desde el punto de vista energético y muy automatizado, que ha creado un paisaje vitícola homogéneo, con un marco de plantación dominante (2,4 m para las calles, y 1,20 m entre cepas), con sistema de formación en espaldera, el mismo que, en la actualidad, domina en el mundo, sobre todo en los nuevos países productores. Asimismo, frente al modelo dominante, estandarizado, una parte de la nueva viticultura reivindica un regreso a la tradición, a las variedades autóctonas, a marcos de plantación y de formación singular y a una gestión ecológica de las viñas.

\subsection{Identidad territorial e indicaciones geográficas protegidas. Variedades locales versus variedades viníferas globales}

Las variedades vinícolas insulares se caracterizan por su diversidad. Hasta un total de 42 variedades viníferas aparecen en 2012 en el Registro Vitícola de las illes Balears (Figura 9). A pesar de la riqueza en variedades autóctonas, sólo aparecen un total de 7 variedades propias: manto negro, callet, Premsal blanc, fogoneu, gorgollassa, giró ros, como viníferas y el calop, variedad de uva de mesa, que sólo equivalen a un $17 \%$ del conjunto. Dominan, pues, las 35 variedades foráneas (83\%). En las islas, las variedades autóctonas ocupan 679 ha (39\% del total superficial) y cubren 1762 parcelas (45\% del parcelario vitícola insular). Son dominantes, por tanto, las variedades foráneas que contabilizan un total de 1078 ha (61\% del total superficial) en 2153 parcelas (55\% del parcelario vitícola insular). En su mayoría, tienen una presencia poco significativa (caso del fogoneu con 20,12 has en 140 parcelas) o incluso testimonial (verdejo con 0,5 ha en una sola parcela). De hecho, las diez primeras variedades por su peso superficial cubren 1561 ha lo que representa un 88,9\% del global. En ese conjunto de variedades mayoritarias, las autóctonas equivalen a 648,15 ha (manto negro, callet, premsal blanc, mezcla de variedades) ${ }^{21}$ y están presentes en 1562 parcelas, frente a las alóctonas con 912,8 ha y con presencia en 1558 parcelas.

21 En las plantaciones antiguas que subsisten, y también en algunas nuevas, el callet se mezcla con el fogoneu francés, porque este último tiene dificultades en la polinización. 
Figura 9. Principales variedades viníferas en Baleares

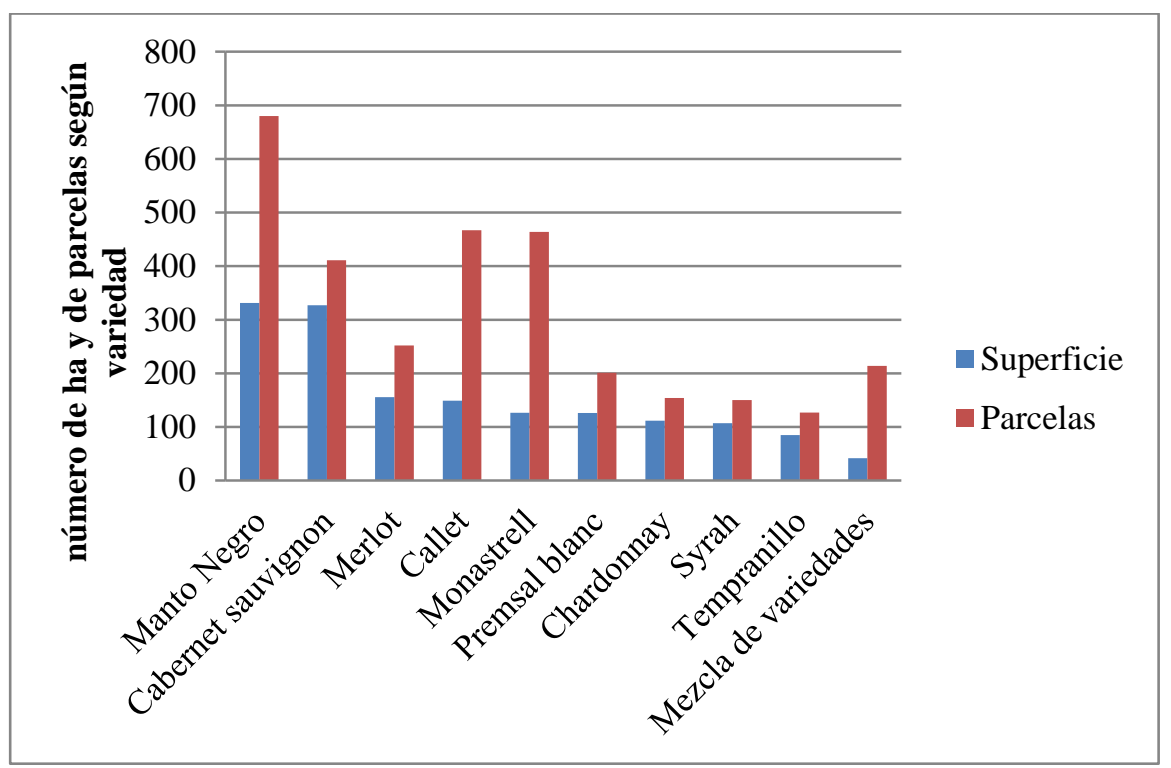

Fuente: elaboración personal a partir de datos del Registro Vitícola de las Illes Balears

El peso mayoritario, entre las variedades foráneas, corresponde a las variedades estandarizadas francesas Cabernet Sauvignon, Merlot, Chardonnay y Syrah, Paradójicamente, el dominio de las variedades globales, se produce en un contexto de regulación extrema de la producción vitícola y bajo el ordenamiento legal de carácter proteccionista de la agricultura local, como son las dos Denominaciones de Origen y demás Indicaciones Geográficas Protegidas, cuya normativa pretende defender la calidad agroalimentaria, ligando la agricultura al territorio.

La DO Binissalem nace a finales de 1990, y se ratificó a nivel oficial en 1991 (BOE núm. 37 de 1711-1991). Agrupaba en 2015 a 15 bodegas, 150 viticultores y 439,07 ha de viña. Su ámbito de producción incluye los municipios de Binissalem, Consell, Santa Maria del Camí, Santa Eugènia y Sencelles. Su Consejo Regulador permite, en su normativa, el cultivo de 15 variedades viníferas. Su objetivo es preservar la singularidad de sus caldos, razón por la cual se exige que los vinos producidos tengan un $30 \%$ de manto negro en el caso de los tintos y un $50 \%$ de premsal blanc en el caso de los vinos blancos, ambas variedades autóctonas. De hecho, aunque el abanico de las variedades foráneas es mayoritario (10 foráneas frente a 5 autóctonas), su normativa es la única en la que se da preferencia a las variedades autóctonas.

Más reciente, la DO del Pla y Llevant se creó en el año 1999. Abarca los municipios de Algaida, Ariany, Artà, Campos, Capdepera, Felanitx, Llucmajor, Manacor, Maria de la Salut, Montuïri, Muro, Petra, Porreres, Sant Joan, Sant Llorenç des Cardessar, Santa Margalida, Sineu y Villafranca. La característica de la DO de Pla y Llevant es la dispersión del área cultivada y de la industria de transformación (Figura 11). Esa dispersión en la localización de viñas y cellers -a excepción de lo que ocurre en Porreres, Felanitx y Manacor- responde a la nueva lógica del sector, una suma de 
pequeñas iniciativas individuales que aúnan cultivo de la vid y elaboración del vino. Reúne un total de 15 cellers, 125 viticultores y 248,63 ha de viña. Con una reglamentación muy flexible, las normas de producción permiten la producción de vino con 19 variedades, 13 foráneas, y 6 autóctonas. Entre éstas últimas destaca el fogoneu por su singularidad, variedad que en la zona tuvo un peso muy significativo en el pasado. De hecho, en las plantaciones viejas éste convive con el callet. Sin embargo, esas reglas no premian en su articulado la plantación de variedades locales.

Figura 10. Mapa de distribución de las parcelas de viñedo ocupadas en 2012 por las variedades Cabernet Sauvignon, Callet y Manto Negro

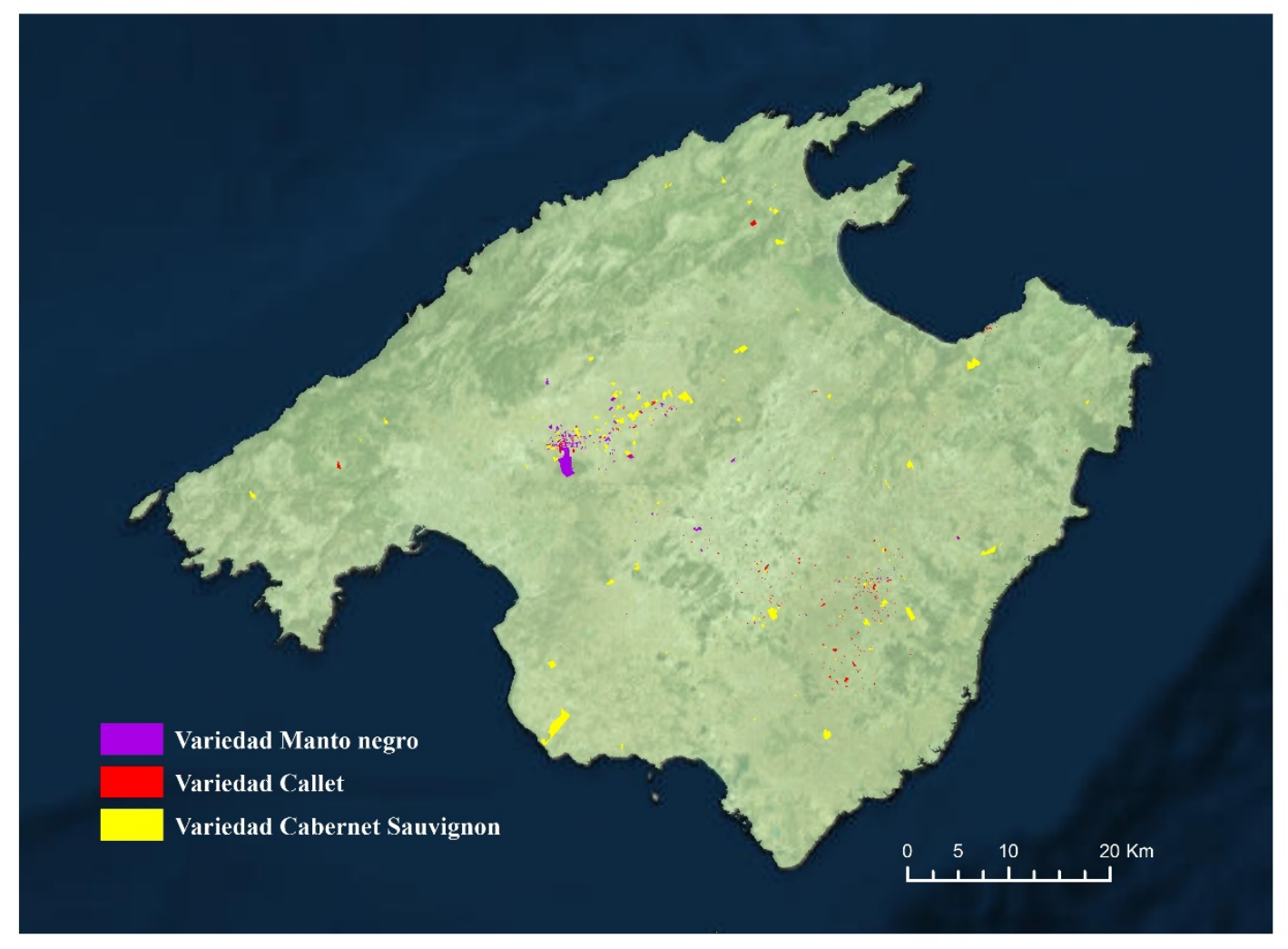

Fuente: elaboración personal a partir de datos de 2012 del Registro Vitícola de las Illes Balears

Coexisten las DO con otras indicaciones geográficas, como son Vi de la Terra Mallorca, Vi de la Terra Costa Nord y Vi de la Terra Illes Balears. La IG Vi de la Terra Mallorca se regula por el pliego de condiciones aprobado en la Orden 22055, de 6 de novembre de 2013. Su reglamentación permite 21 variedades viníferas. Vi de la Terra illes Balears, se aprobó en la Orden 1955, de 29 de gener de 2013. Las variedades de uva permitidas son 19, con claro dominio de las variedades foráneas. Destaca la presencia de la malvasía, variedad autóctona blanca. Por último, la IG Protegida Serra de Tramuntana Costa Nord abarca 18 municipios de la Sierra Norte, acoge a 3 bodegas situadas en los municipios de Estellencs y Banyalbufar dedicados a la producción de vino de uva de malvasía de viñas plantadas en pequeñas parcelas abancaladas en las laderas septentrionales de esos parajes de la Serra de Tramuntana. Está regulada por la Orden 21779, de 
7 de noviembre de 2013. La normativa autoriza 14 variedades, con dominio de las foráneas sobre las locales. El patrón es repetitivo, con ausencias y presencias que se deben, fundamentalmente, a las reivindicaciones de los productores y viticultores acogidos a cada una de las tres IG existentes.

Figura 11. Mapa de distribución de las parcelas de viñedo pertenecientes a la DO Binissalem y a la DO Pla i Llevant

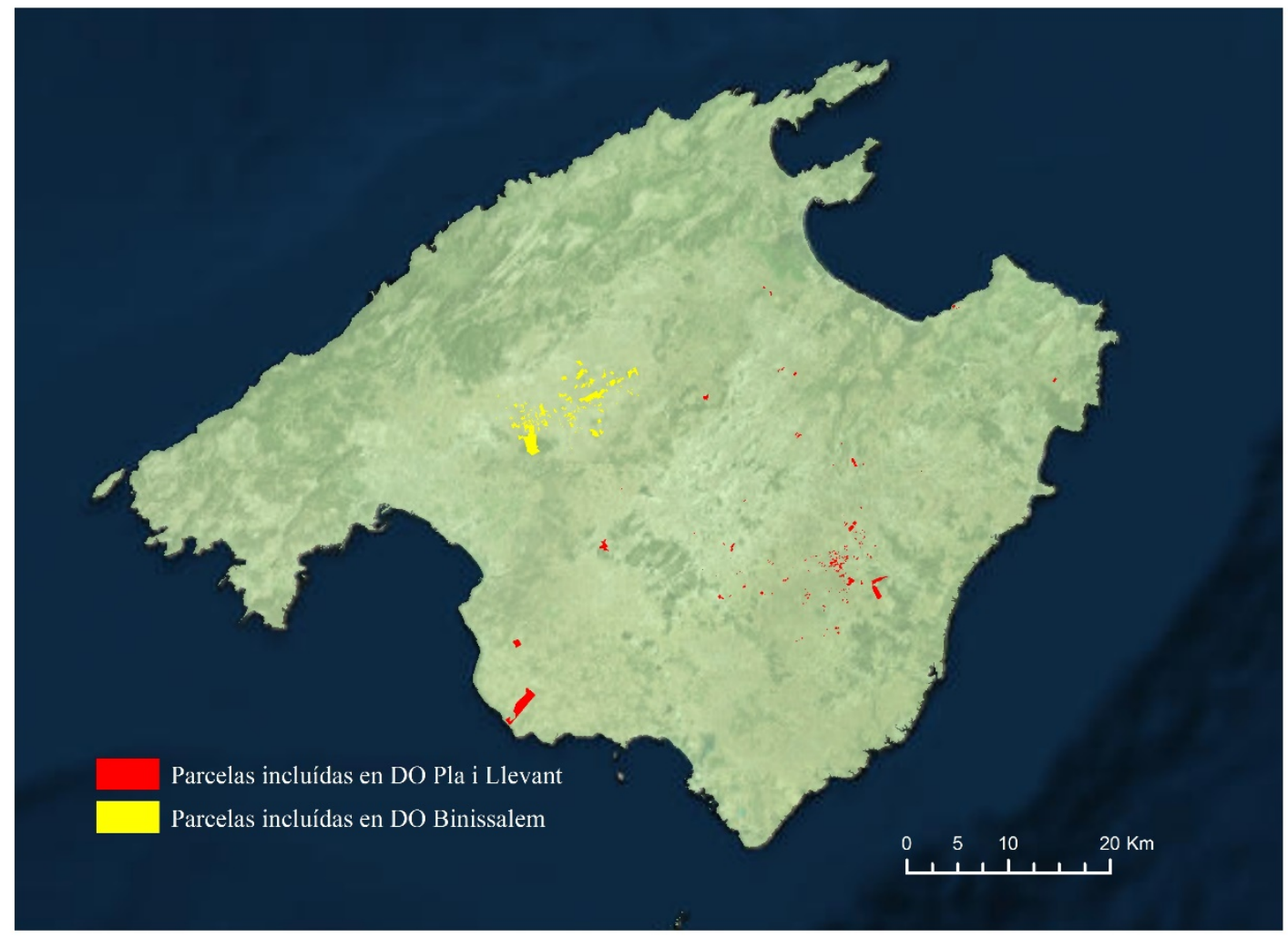

Fuente: elaboración personal a partir de datos de 2012 de la DO Binissalem y de la DO Pla i Llevant

En realidad, tanto las DO existentes como las IG se caracterizan por una gran flexibilidad en su normativa sobre variedades permitidas, jugando un papel crucial las variedades globales. Mientras, las variedades locales permitidas (entre 5 y 7) juegan un papel menor. Sólo la Denominación de Origen Binissalem, da prioridad a las variedades locales, pues su normativa es exigente en el peso del manto negro y del premsal blanc en la producción de vino tinto y blanco, y, además, diferencia en su articulado entre variedades permitidas y variedades preeminentes.

Por otra parte, en las normativas reguladoras se apela a factores naturales (Geología y suelo, microclima) y culturales y humanos, como justificantes de la idiosincrasia de los vinos producidos. Entre estos últimos se apela a la historia, con referencias que se remontan al domino romano de las islas, o, también, a la alta consideración que en las cortes europeas y entre los viajeros románticos del siglo XIX tuvo el vino de malvasía de la Serra de Tramuntana. Se trata de la construcción social de una imagen, dónde la Historia y el mito se entremezclan, pero que tiene escasa fundamentación 
(Gade, 2008). No ha habido una continuidad histórica en los procedimientos de elaboración de los caldos y en la selección de las plantas. La etapa vitícola previa -la industrial y proto-industrial- que se inicia con la reconstrucción del viñedo isleño tras la crisis de la filoxera, se caracterizó por apostar por variedades productivas, destinadas a la fabricación de caldos rosados para el consumo diario.

\section{Conclusiones}

En el trabajo presentamos algunos resultados de la investigación sobre el cambio de paradigma agrícola acontecido desde el impulso modernizador que supuso la Revolución Verde, allá en los años sesenta, coincidiendo con la irrupción del turismo de masas, hasta la actualidad, con un mundo rural multifuncional. En el mismo llevamos a cabo una descripción sobre las transformaciones que han tenido lugar en el subsector vitivinícola, apoyada sobre todo en la elaboración de fuentes primarias (encuesta y datos del Registro Vitícola), comprobándose que los cambios socio-económicos en general y los propios del sector, repercuten claramente sobre los paisajes vitícolas insulares. La mecanización del campo introdujo en los años sesenta cambios en los marcos de plantación de las viñas y la motorización. Además, el nuevo mercado turístico, fue el acicate para reafirmar el carácter industrial de las bodegas. Por otro lado, la etapa actual del cultivo de la vid y de la industria del vino se inicia con los planes de restructuración del viñedo tras la integración en la Unión Europea y está marcada por la homogeneidad paisajística del nuevo sistema de formación de la viña, por el uso de variedades estandarizadas a nivel global y por la atomización de la industria de transformación, que ha sido posible gracias al cambio tecnológico y, sobre todo, a la segmentación de la demanda del mercado del vino. Las similitudes y diferencias entre las dos etapas quedan sintetizadas en la tabla (Tabla 3) que sigue a continuación: 
Tabla 3. Síntesis de los principales cambios

\begin{tabular}{|c|c|c|}
\hline Características & Modelo industrial $^{22}$ & Transición post-productivista \\
\hline Marco de plantación & $\begin{array}{l}1,60 \mathrm{~m} . \times 1.60 \mathrm{~m} \text {. en la Zona } \\
\text { Alta y } 2 \mathrm{~m} . \text { x } 1 \mathrm{~m} \text {. en la Zona } \\
\text { Baja }\end{array}$ & $\begin{array}{l}\text { 2, } 4 \text { m x 1,2 m. como único } \\
\text { marco de plantación. Uso de } \\
\text { marcos antiguos entre los } \\
\text { viticultores ecológicos y } \\
\text { biodinámicos }\end{array}$ \\
\hline Sistema de formación & $\begin{array}{l}\text { Viña en vaso. Diferencias en } \\
\text { el sistema de conducción } \\
\text { entre la Zona Alta y la Zona } \\
\text { Baja }\end{array}$ & $\begin{array}{l}\text { Difusión generalizada de la viña } \\
\text { en espaldera con doble cordón. } \\
\text { Uso minoritario de sistemas de } \\
\text { formación tradicionales. }\end{array}$ \\
\hline Variedades de uva & $\begin{array}{l}\text { Dominio absoluto de las } v \text {. } \\
\text { autóctonas: callet y fogoneu } \\
\text { en la Zona Baja, manto negro } \\
\text { y premsal blanc en la Zona } \\
\text { Alta }\end{array}$ & $\begin{array}{l}\text { Reivindicación de las v. } \\
\text { autóctonas en las IGP, pero } \\
\text { aceptación y difusión generalizada } \\
\text { de las variedades estándar de } \\
\text { origen francés. }\end{array}$ \\
\hline Sistemas de cultivo & $\begin{array}{l}\text { Mecanización (tractores de } \\
50 \mathrm{CV} \text { ), mano de obra y } \\
\text { pervivencia de la tracción } \\
\text { animal }\end{array}$ & $\begin{array}{l}\text { Mecanización (tractores de } 60 \text { a } \\
90 \mathrm{CV} \text { ), mecanización de la } \\
\text { vendimia en grandes bodegas. } \\
\text { Uso minoritario de sistemas de } \\
\text { cultivo tradicionales }\end{array}$ \\
\hline $\begin{array}{l}\text { Distribución geográfica del } \\
\text { cultivo }\end{array}$ & $\begin{array}{l}\text { Concentración del cultivo en } \\
\text { la zona Alta y, sobre todo, en } \\
\text { la Zona Baja. Tendencia a la } \\
\text { concentración de la } \\
\text { producción en pocas } \\
\text { bodegas (34 en 1987). } \\
\text { Pervivencia de un modelo } \\
\text { dual industrial-artesano. }\end{array}$ & $\begin{array}{l}\text { Pervivencia de la concentración } \\
\text { del cultivo y aparición de pautas } \\
\text { de dispersión geográfica casi } \\
\text { generalizada en el territorio. } \\
\text { Mayor concentración de viña en } \\
\text { la DO de Binissalem que en la } \\
\text { DO de Pla i Llevant Atomización } \\
\text { de la producción (56 bodegas en } \\
\text { 2015). }\end{array}$ \\
\hline Industria de transformación & $\begin{array}{l}\text { Aumento de la capacidad de } \\
\text { producción de las bodegas } \\
\text { (Celler Cooperatiu, Trevin, } \\
\text { S.A.). Maquinización del } \\
\text { proceso de producción } \\
\text { (bombas de trasiego, grandes } \\
\text { depósitos). Vino a granel y } \\
\text { consolidación de plantas de } \\
\text { embotellado }\end{array}$ & $\begin{array}{l}\text { Sistemas de fermentación en frío, } \\
\text { nueva tecnología en control de } \\
\text { temperaturas, depósitos de acero } \\
\text { inoxidable, Vino embotellado y } \\
\text { enumerado. Proliferación de } \\
\text { bodegas de baja capacidad, con } \\
\text { viñedo propio. Creciente } \\
\text { importancia de la exportación de } \\
\text { los caldos mallorquines }\end{array}$ \\
\hline IG & & $\begin{array}{l}\text { DO Binissalem, DO Pla y Llevant, } \\
\text { Vi de la Terra Mallorca, Vi de la } \\
\text { Terra Costa Nord y Vi de la Terra } \\
\text { llles Balears }\end{array}$ \\
\hline
\end{tabular}

Fuente: elaboración propia

No obstante, en la hipótesis inicial, planteábamos que los cambios recientes, acontecidos tras el ingreso de España en la Unión Europea, mostraban signos evidentes de la transformación postproductiva del sector. Pero, en su puesta en escena insular el paradigma de la calidad ofrece lagunas y contradicciones. Inspirándonos en un trabajo de A. Mather et al. (2006), hemos medido

22 Las características del modelo de la etapa industrial en la vitivinicultura insular fueron explicadas en un artículo que precede a este trabajo (Binimelis, 2014). 
de forma cualitativa la intensidad de los cambios de tipo post-productivo, o no-productivo, observados en la reciente evolución del sector vitivinícola, como sigue a continuación en el cuadro (Tabla 4).

Tabla 4. Intensidad del tránsito post-productivista en el sector vitícola

\begin{tabular}{|c|c|c|}
\hline Autores & Características & $\begin{array}{c}\text { Intensidad del } \\
\text { cambio }\end{array}$ \\
\hline \multirow{6}{*}{ Ilbery y Bowler (1998) } & Reducción de la producción & +++ \\
\hline & Disminución de los subsidios & $-\cdots$ \\
\hline & $\begin{array}{l}\text { Producción creciente en un mercado } \\
\text { internacional competitivo }\end{array}$ & +++ \\
\hline & De la intensificación a la extensificación & -- \\
\hline & De la concentración a la dispersión & +++ \\
\hline & De la especialización a la diversificación & $+? ?$ \\
\hline \multirow{5}{*}{ Evans et al. (2002) } & Patrones productivos de dispersión & +++ \\
\hline & $\begin{array}{l}\text { Incremento de la diversificación agrícola y de } \\
\text { la pluriactividad }\end{array}$ & + \\
\hline & $\begin{array}{l}\text { Insistencia en la calidad en la producción de } \\
\text { alimentos }\end{array}$ & +++ \\
\hline & $\begin{array}{l}\text { Progresiva tendencia al desarrollo de una } \\
\text { agricultura sostenible amparada en las } \\
\text { políticas agroambientales }\end{array}$ & + \\
\hline & $\begin{array}{l}\text { Decremento del apoyo financiero de la } \\
\text { Administración hacia la agricultura }\end{array}$ & - - \\
\hline
\end{tabular}

Respuesta positiva: +=bajo; $++=$ medio; $+++=$ alto. Respuesta negativa: - =bajo; - - =medio; - - =alto. Falta de información:? = bajo; ??= medio; ???=alto

Fuente: adaptado de Mather et al. (2006)

al caso de la transición post-productivista del sector vitivinícola en Mallorca

A pesar de la repercusión mediática que tiene en la actualidad el sector vitivinícola en Mallorca, la producción de vino y la superficie vitícola ha disminuido, en comparación a la etapa precedente. Según datos del Registro Vitícola de las Illes Balears, había en 2012 un total de 1.802,91 ha de viña, mientras que en 1982 eran 3066.

No obstante, la ayuda al sector a través de subsidios ha continuado. De hecho, buena parte de su resurgimiento se debe al apoyo de la Administración a través de los planes de reestructuración del viñedo, que han catapultado un nuevo paisaje vitícola, de características homogéneas en cuanto a sistema de formación (espaldera) y un marco de plantación universal que ha eliminado las diferencias locales. Buena parte de las nuevas plantaciones cuentan con sistema de regadío por goteo, como apoyo durante la canícula estival, pero muy discutible desde el punto de vista ambiental. En conjunto, ha supuesto el triunfo de una viticultura intensiva y muy tecnificada, que facilita la automatización creciente de las labores. 
Sólo la irrupción de la vitivinicultura ecológica ha compensado el carácter intensivo y paisajísticamente homogeneizador que la nueva apuesta vitícola ha introducido. Esta modalidad reivindica marcos de plantación tradicionales en aras a la singularidad, apuesta por el uso casi exclusivo de variedades locales (incluso las pre-filoxéricas), recupera técnicas de cultivo y sistemas de laboreo tradicionales (tracción animal incluida), huyendo de los fungicidas sistémicos, de la escarda química y de los sistemas de riego por goteo que también esquilman los acuíferos insulares. En definitiva, su apuesta es por sistemas extensivos tradicionales respetuosos con el medio ambiente y la herencia del pasado, frente al nuevo modelo dominante de carácter intensivo, paisajísticamente homogéneo y poco sostenible desde el punto de vista ambiental.

A excepción del viñedo de la actual Denominación de Origen Binissalem, la distribución geográfica de la superficie vitícola se caracteriza por su dispersión que coincide con la atomización de la industria de transformación. Cuando se realizó la encuesta, había en la isla hasta un total de 56 bodegas, cifra indicativa de dicha característica.

Desde la investigación realizada, tenemos escasas evidencias empíricas sobre la diversificación de la producción. Cierto es que, cada bodega, muchas de producción limitada, casi artesanal, buscan el valor añadido desde la singularidad del producto que ofrecen. No obstante, el hallazgo de la singularidad, puede ser muchas veces el resultado de un ejercicio de marketing y de la construcción de un discurso propio. Algunas de ellas, apuestan, a su vez, por incluir la bodega en rutas turísticas convenidas, compaginando, unas pocas. la actividad agraria con servicios de restauración o incluso de hospedaje. Aun así, el grado de multifuncionalidad del sector en Mallorca no ha alcanzado un desarrollo significativo.

Como hemos comprobado, a pesar de la diversidad de las variedades aceptadas por las distintas Denominaciones de Origen e Indicaciones Geográficas Protegidas, las variedades globales, estandarizadas, como el Cabernet Sauvignon son las mayoritarias en el actual mapa vitícola insular. Sólo las bodegas más exclusivas y, casi siempre, de gestión ecológica, han hecho una apuesta clara con las variedades autóctonas.

Por otra parte, el desarrollo tecnológico adquirido por la industria de transformación y las prácticas vinícolas actuales (vendimia y selección manual, mesa de selección, sistemas de refrigeración, fermentación controlada), el control de calidad impuesto desde el reglamento de las DO o IGP, la decidida apuesta por la exportación, han permitido al vino mallorquín competir en un nicho de mercado de calidad.

En definitiva, la transformación post-productiva del sector vitícola mallorquín ofrece luces y sombras a tenor de los resultados obtenidos y de su proyección en las características consensuadas sobre su significado. 
Declaración responsable: El autor declara que no existe ningún conflicto de interés en relación con la publicación de este artículo. 


\section{Bibliografía}

Junta Provincial de Ordenación Económico-Social de Baleares (1947). Anteproyecto de ordenación económico-social de Baleares 1947-1951. Palma.

Almstedt, A., Brouder, P., Karlsson, S., \& Lundmark, L. (2014). Beyond post-productivism: from rural policy discourse to rural diversity. European countryside, 6(4), 297-306.

Armesto López, X. A., \& Martín, B. G. (2006). Tourism and quality agro-food products: an opportunity for the Spanish countryside. Tijdschrift voor economische en sociale geografie, 97, 166-177. https://doi.org/10.1111/j.1467-9663.2006.00510.x

Barceló Pons, B. (1959). El desarrollo del cultivo de la vid en Mallorca. Boletín de la Cámara Oficial de Comercio, Industria y Navegación de Palma de Mallorca, 624, 83-90.

Barham, E. (2003). Translating terroir: the global challenge of French AOC labeling. Journal of Rural Studies, 19(1), 127-138.

Binimelis Sebastián, J. (1990). Evolució del cultiu de la vinya i de la producción vinícola a les illes Balears (Master's Thesis, Universitat de les illes Balears, Spain).

Binimelis Sebastián, J. (1999). El cultivo de la vid en Mallorca. Problemática del subsector después del ingreso del Estado Español en la Unión Europea. Viticultura y Enología Profesional, 61, 24-35. Binimelis Sebastián, J. (2014). De la viticultura tradicional a la viticultura industrial. Cambios en el paisaje vitícola de la isla de Mallorca. Scripta Nova, XVIII(484). http://dx.doi.org/10.1344/sn2014.18.15069

Bowen, S., \& De Master, K. (2011). New rural livelihoods or museums of production? Quality food initiatives in practice. Journal of Rural Studies, 27(1), 73-82.

Cañizares Ruiz, Ma C., \& Ruiz Pulpón, Á. R. (2014). Evolución del paisaje del viñedo en Castilla-La Mancha y revalorización del patrimonio agrario en el contexto de la modernización. Scripta Nova, XVIII(498). hitp://dx.doi.org/10.1344/sn2014.18.15082

Carmona, J. et al. (ed.). (2001). Viñas, bodegas y mercados. El cambio técnico en la vitivinicultura española. 1850-1936. Zaragoza: Prensas Universitarias.

Colomé Ferrer, J. (2001). El sector vitícola español durante la segunda mitad del siglo XIX y el primer tercio del siglo XX. El impacto de la demanda francesa. La crisis ecológica y el cambio técnico. In Carmona, J. et al. (Ed.), Viñas, bodegas y mercados. El cambio técnico en la vitivinicultura española. 1850-1936 (pp. 39-62). Zaragoza: Prensas Universitarias.

Consejo Económico Sindical Provincia (1959). Ponencias y conclusiones del IIl pleno del Consejo Económico Sindical Provincial de Baleares. Palma. 
Delaplace, M., \& Gatelier, E. (2014). Patrimonialisation individuelle et collective et développement de l'œnotourisme en Bourgogne. Territoire en mouvement, 21, 40-53. Retrieved from http://tem.revues.org/2283

Delfosse, C. (2011). La patrimonialisation des produits dits de terroir. Anthropology of food, 8. Retrieved from http://aof.revues.org/6772

Dellier, J., Rouvellac, E., \& Guyot, S. (2013). Le vignoble sud-africain dans l'ère post-apartheid, entre transformation et continuité. EchoGéo, 23. http://dx.doi.org/10.4000/echogeo.13343

Dougherty, P. H. (2012). Introduction to the Geographical study of Viticulture and Wine production. In dougherty, P. H. (Ed). The Geography of wine. Regions, Terroir and Techniques (pp. 3-36). London: Springer.

Dougherty, P. H. (Ed.) (2012). The Geography of wine. Regions, Terroir and Techniques. London: Springer.

Evans, N. (2001). Reflexiones en torno al modelo agropecuario productivista. In F. García Pascual, El mundo rural en la era de la globalización: incertidumbres y potencialidades (pp. 45-64).. Madrid: Ministerio de Agricultura, Pesca y Alimentación.

Evans, N., Morris, C., \& Winter, M. (2002). Conceptualizing agriculture: a critique of postproductivism as the new orthodoxy. Progress in Human Geography, 26(3), 313-332.

Fanet, J. (2007). Definition du terroir. In XXX World Congress of vine and Wine. Groupe d'experts, environnement viticole et évolution climatique. Budapest: OIV. vol. 6, pp. 1-6.

Fernández, E. (2012). Especialización en baja calidad: España y el mercado internacional del vino, 1950-1990. Historia Agraria, 56, pp. 41-76.

Fernández Portela, J. (2012). Cambios en la industria y en el paisaje vitivinícola de la Denominación de Origen de Cigales (Castilla y León, España). Estudios Geográficos, LXXIII(272), pp. 6390. http://dx.doi.org/10.3989/estgeogr.201203

Fernández Portela, J., \& García Velasco, M.A. (2014). Las bodegas tradicionales: Patrimonio olvidado en la cultura del vino en la Denominación de Origen de Cigalés (Castilla y León, España). Geographicalia, 65, pp. 61-86.

Ferrer Alòs, L. (2001). Viticultores no comerciantes. Notas sobre la evolución de la viticultura en la Catalunya Central. In Carmona, J. et al. (Ed.), Viñas, bodegas y mercados. El cambio técnico en la vitivinicultura española, 1850-1936 (pp. 69-89). Zaragoza: Prensas Universitarias.

Gade, D. W. (2004). Tradition, Territory, and Terroir in French Viniculture: Cassis, France, and Appellation Contrôlée. Annals of the Association of American Geographers, 94(4), pp. 848-867. 
Hervieu, B. (1996). Los campos del futuro. MAPA, Secretaría General Técnica.

Hinnewinkel, J.-C. (2007). L'avenir du terroir: gérer de la complexité par la gouvernance locale. Méditerranée, 109, 17-22. http://dx.doi.org/10.4000/mediterranee.106

Holloway, L., \& Kneafsey, M. (2004). Producing-Consuming Food: Closeness, Connectedness and Rurality in Four 'Alternative' Food Networks. In L. Holloway \& M. Kneafsey (Eds.), Geographies of Rural Cultures and Societies (pp. 262-282). Aldershot: Ashgate.

Huetz de Lemps, A. (2000). La résurrection des vignobles du Duero en Espagne / The revival of the Duero vineyards in Spain. Annales de Géographie, 109(614/615), 488-504. Retrieved from http://www.jstor.org/stable/23455762

Ilbery, B.W., \& Bowler, I.R. (1998). From agricultural productivism to postproductivism. In B.W. Ilbery \& I.R. Bowler (Eds.), The Geography of Rural Change (pp. 57-84). Harlow: Adisson Wesley Longman Limited.

Conselleria d'Agricultura, Medi Ambient i Territori (n.d.). Denominacions i Marques. Retrieved from www.illesbalearsqualitat.es/ibgfront/iqua

Mather, A.S, Hill, G., \& Nijnik, M. (2006). Post-productivism and rural land use: cul de sac or challenge for theorization?, Journal of Rural Studies, 22, 441-455.

Molinero, F., \& Cascos, C. (2011). La Ribera del Duero: Los paisajes de la pujanza del viñedo. In F. Molinero, J. Ojeda \& J. Tort (Coords.), Los paisajes agrarios de España Caracterización, evolución y tipificación (pp. 350-371). Madrid: Ministerio de Medio Ambiente y Medio Rural y Marino.

Morris, C. (2004). Lost Words, Lost Worlds? Cultural Geographies of Agricultur. In L. Holloway \& M. Kneafsey (Eds.), Geographies of Rural Cultures and Societies (pp. p. 241-261). Aldershot: Ashgate.

Morris, C., \& Evans, N. (1999). Research on the Geography of agricultural change: redundant 0 revitalized. Area, 31, 349-358.

Ojeda, J., \& Silva, R. (2002). Efectos de la implantación del modelo agroambiental y postproductivista en la Sierra Morena onubense, Estudios Geográficos, LXIII(246), 69-100.

Pan-Montojo, J. (2009). Las vitiviniculturas europeas: de la primera a la segunda globalización. Mundo Agrario, 9(18). Retrieved from hitp://www.scielo.org.ar/scielo.php

Pinilla Navarro, V. (2001). Cambio técnico en la vitinicultura aragonesa. 1850-1936. Una aproximación desde la teoría de la innovación inducida. In J. Carmona et al. (Ed.), Viñas, bodegas y mercados. El cambio técnico en la vitivinicultura española. 1850-1936 (pp. 89-114). Zaragoza: Prensas Universitarias. 
Piqueras Haba, J. (2001). Propiedad vitícola y cambio técnico en la meseta de Requena. In Carmona, J. et al. (ed.), Viñas, bodegas y mercados. El cambio técnico en la vitivinicultura española. 1850-1936 (pp. 115-140). Zaragoza: Prensas Universitarias.

Ruiz Pulpón, A. R. (2013). Producción agroalimentaria de calidad y postproductivismo agrario: El caso de los vinos de pago en Castilla-La Mancha. Anales de Geografía de la Universidad Complutense, 33(2), 137-154.

Ruiz Pulpón, Á. R (2013). El viñedo en espaldera: nueva realidad en los paisajes vitivinícolas de Castilla-La Mancha. Boletín de la Asociación de Geógrafos Españoles, 63, 249-270.

Sabio Alcutén, A. (2001). Transformaciones vitícolas y enológicas desde el tipo de asociacionismo agrario: el campo de Cariñena, 1870-1970. In Carmona, J. et al. (Ed.), Viñas, bodegas y mercados. El cambio técnico en la vitivinicultura española. 1850-1936 (pp. 209-238). Zaragoza: Prensas Universitarias.

Saumell Soler, A. (2001). Propietarios, comerciantes y técnicos: la Estación Enológica de Villafranca del Penedès. In Carmona, J. et al. (Eds.), Viñas, bodegas y mercados. El cambio técnico en la vitivinicultura española. 1850-1936 (pp. 327-348). Zaragoza: Prensas Universitarias.

Schirmer, R. (2011). Le géographe et l'expertise dans le domaine des vins. In S. Wolikow \& O. Jacquet (Coord.), Colloque international Chaire UNESCO Culture et traditions du vin. DeJules Guyot à Robert Parker: 150 ans de construction des territoires du vin, Nov 2008 (pp. 91-108). Dijon: Editions Universitaires de Dijon.

Tilzey, M. \& Potter, C. (2008). Productivism versus Post-Productivism? Modes of Agri-Environmental Governance. In G. M. Robinson (Ed.), Post-Fordist Agricultural Transitions. In Sustainable Rural Systems Sustainable Agriculture and Rural Communities (pp. 41-66). Glasgow: Ashgate

Unwin, T. (2001). El vino y la viña. Barcelona: Tusquets Editores.

Unwin, T. (2012). Terroir. At the heart of Geography. In P. H. Dougherty (Ed.), The Geography of wine. Regions, Terroir and Techniques (pp. 37-48). London: Springer.

Vaudour, E., \& Shaw, A. (2005). A worldwide perspective on viticultural zoning. South Africa Journal of Enology and Viticulture, 26(2), 106-115.

Wilson, G. A., \& Burton, R. J.F. (2015). 'Neo-productivist' agricultura: Spatio-temporal versus structuralist perspectives. Journal of Rural Studies, 38, 52-64. 